\title{
An aptamer that binds efficiently to the hemagglutinins of highly pathogenic avian influenza viruses (H5N1 and H7N7) and inhibits HA-glycan interactions
}

Emi Suenaga and Penmetcha K.R. Kumar

Biomedical Research Institute, Central 6, National Institute of Advanced Industrial Science and Technology, 1-1-1 Higashi, Tsukuba City 305-8566, Ibaraki, Japan

Running title: Aptamer against the highly pathogenic influenza virus

${ }^{*}$ Correspondence should be addressed to:

Dr. Penmetcha K. R. Kumar

RNA processing group, Biomedical Research Institute, National Institute of Advanced Industrial Science and Technology, Central 6, 1-1-1 Higashi, Tsukuba City 305-8566, Ibaraki, Japan.

Tel/Fax.: +81-298-61 6773

Email: pkr-kumar@aist.go.jp 


\section{ABSTRACT}

Highly pathogenic avian influenza (HPAI) H5 and $\mathrm{H} 7$ viruses have ravaged the poultry industry in numerous countries in Asia, Europe, Africa and the Middle East and have resulted in the deaths of millions of birds. Although HPAI H5N1 viruses currently remain avian viruses, they are continuously evolving and have the potential to become pandemic-type viruses capable of human-human transmission. To develop specific reagents to allow better preparedness against this threat, we selected an aptamer (8-3) from a completely random RNA pool that binds with high affinity $\left(\sim K_{D} 170\right.$ picomolar) to the HAs derived from HPAI H5N1 (A/H5N1/Vietnam/1194/2004 and A/H5N1/Indonesia/05/2005) and H7N7 (A/H7N7/Netherlands/219/2003) influenza A viruses. Aptamer 8-3 was able to efficiently distinguish HAs derived from subtypes of influenza A virus other than H5 and H7. Aptamer 8-3 was analyzed further to assess its ability to interfere with HA-glycan interactions using our previously established SPR-based competitive assay, and we found that aptamer 8-3 efficiently interferes with HA-glycan binding $\left(E_{50} \sim 25 \mathrm{nM}\right)$. To derive shorter variants for other applications, aptamer 8-3 was shortened to a 44-mer by deletion analyses. The shortened aptamer, 8-3S, retains the full-length aptamer's affinity and specificity for its cognate HAs and also interferes with HA-glycan interactions. These studies suggest that aptamer 8-3S should be studied further to explore its potential applications not only in surveillance and diagnosis but also in the development of H5N1- and H7N7-specific virucidal products that interfere with virus-host interactions to contain future H5N1 and H7N7 pandemics.

Key words: Aptamer, H5N1, H7N7, Influenza virus, Hemagglutinin

\section{Introduction}

Influenza viruses belong to the Orthomyxoviridae family and are classified into three different types (A, B, and C) based on antigenic differences in the nucleocapsid (NP) and matrix (M) proteins. Among these viruses, only influenza A viruses are able to infect different animal species, including humans, horses, swine, and a wide variety of aquatic birds. Influenza A viruses are further 
categorized into subtypes based on the antigenic characteristics of two surface glycoproteins, hemagglutinin (HA) and neuraminidase (NA). Currently, 16 HA subtypes (H1-H16) and 9 NA subtypes (N1-N9) have been identified [1]. All these variants are maintained in avian species, leading to the proposal that all mammalian influenza A viruses have originated from avian influenza viruses $[2,3]$.

HA is responsible for both receptor (glycan) binding and membrane fusion during cell entry, and NA has receptor-destroying activity during virus release. Although the primary sequences of HAs are less than $30 \%$ conserved, these proteins have similar three-dimensional structures. HA is a homotrimer composed of two disulfide-linked polypeptide chains, HA1 and HA2, that are formed after cleavage at the proteolytic site by host trypsin-like proteases such as furin. The HA1 protein of influenza viruses binds to glycans on the host cell surface through terminal sialic acid (Sia) moieties with $\alpha 2-3$ and $\alpha 2-6$ linkages. This binding is essential for the infectivity, transmission and virulence of influenza viruses $[4,5]$. The HAs derived from avian influenza viruses bind specifically to a2-3 Sia glycans, whereas HAs derived from human-adapted influenza viruses prefer to bind to $\alpha 2-6$ Sia glycans [6]. It has been suggested that the HAs of avian influenza viruses must adapt to bind to $\alpha 2-6$ Sia glycans to achieve efficient transmission among humans [7]. In pandemic avian influenza viruses, the HA appears to change its glycan specificity from $\alpha 2-3$ Sia to $\alpha 2-6$ Sia by adjusting the glycan-binding pocket through a combination of mutations.

Due to the infidelity of the influenza virus-encoded polymerase, point mutations are continuously introduced into the single-stranded RNA segments of influenza virus, leading to "antigenic drift" and thereby changing the antigenicity of the HA or NA of the virus. Alternatively, antigenic shift occurs when RNA 
segments are exchanged between the strains to create new hybrid strains. Such reassortment events appear to be important in the development of new influenza strains that cause pandemics [8-10]. For example, the pandemic influenza strains of 1957 and 1968 were reassortants containing avian segments for HA, polymerase basic 1 protein, and NA in a human-virus genetic background [11].

Currently, only three HA subtypes-H1N1, H2N2, and H3N2-have successfully adapted to humans [12-14]. During the past four decades, a growing number of human cases of avian influenza virus infection have been identified, including infections with the H5N1, H7N2, H7N7, and H9N2 subtypes [15-17]. Of these viruses, the $\mathrm{H} 5 \mathrm{~N} 1, \mathrm{H} 7 \mathrm{~N} 2$, and $\mathrm{H} 7 \mathrm{~N} 7$ viruses are classified as highly pathogenic avian influenza viruses (HPAl) because they can affect multiple organs and cause up to $100 \%$ mortality within 48 hours in the case of infected chickens. It has been revealed that acquiring an easily cleavable site (for multiple host trypsin-like proteases) between the HA1 and HA2 subunits is an important criterion for becoming an HPAI virus [18]. The introduction of multiple arginine and lysine residues between the HA1 and HA2 subunits makes the HAO (uncleaved) form labile to a wide range of host proteases produced by different cell types. The conversion of HAO (uncleaved form) into the HA1 and HA2 subunits by host proteases is essential for mediating membrane fusion. Interestingly, all major HPAI strains possess readily cleavable resides (multiple arginine and lysine residues) between the HA1 and HA2 subunits and lack carbohydrate residues near this cleavage site $[19,20]$. Thus, these two features appear to be very important for the efficient conversion of HAO into HA1 and HA2, thus facilitating wider tissue tropism for influenza viruses [21].

For the past 15 years, HPAI H5N1 viruses have affected the poultry industry in numerous countries and have resulted in the deaths of millions of birds. 
Importantly, in 1997, the first human deaths caused by an HPAI H5N1 virus were registered [15]. More than 600 HPAI H5N1 virus infections were reported in 2003. Currently, HPAI H5N1 viruses remain avian viruses, but they are continuously evolving [22-24] and have the potential to become pandemic-type viruses capable of human-human transmission. Considering the urgency of preparedness against a pandemic caused by an HPAI H5N1 virus, it is important to develop specific reagents for applications in surveillance, diagnosis and the development of virucidal products that interfere with the initial virus-host interactions. Earlier, we have reported RNA aptamers that bind specifically to the HAs of different influenza viruses [B/Johannesburg/05/1999, A/Panama/2007/1999 (H3N2), and A/California/04/2009 (H1N1) [25-27]]. These studies showed that these aptamers not only had greater specificity (equilibrium dissociation constants, $K_{D}$, up to the picomolar level) for their cognate HAs but also efficiently distinguished different clades within the subtypes of influenza viruses [25-27]. Moreover, these aptamers were shown to be able to interfere efficiently with HA-glycan interactions and prevent membrane fusion. In the present study, we used in vitro selection with a completely random RNA pool, and we found an RNA aptamer (8-3) that binds with high affinity to the HAs derived from $\mathrm{H} 5 \mathrm{~N} 1$ and $\mathrm{H} 7 \mathrm{~N} 7$ influenza A viruses. Aptamer 8-3 was able to efficiently distinguish other subtypes of influenza A virus. This aptamer was analyzed further to determine its ability to interfere with HA-glycan interactions using our previously established SPR-based competitive assay. We found that aptamer 8-3 efficiently interferes with these interactions. To derive shorter variants for future applications, we performed deletion analyses with aptamer 8-3 (113 nts), and we were able to shorten aptamer 8-3 to a 44-mer. The shortened aptamer, 8-3S, retained the affinity, specificity and ability to interfere 
with HA-glycan interactions of the full-length aptamer. We believe that aptamer 8-3S should be studied further to explore its potential applications in the surveillance and diagnosis of HPAI H5N1 and H7N7 viruses.

\section{Experimental}

\subsection{Materials}

Baculovirus/mammalian cell-expressed recombinant hemagglutinins (HAs) from A/H5N1/Vietnam/1194/2004 (accession no. AAT73273.1), A/H5N1/Indonesia/05/2005 (accession no. ABW06108.1), A/H7N7/Netherlands/219/2003 (accession no. AAR02640.1) and A/H9N2/Hong Kong/1073/99 (accession no. NP_859037.1) were purchased from Sino Biological Inc. (China). Cleavage site deleted HA variants of A/H5N1/Vietnam/1194/2004 and A/H7N7/Netherlands/219/2003 were purchased from Sino Biological Inc. (China) and Prospec-Tany TechnoGene Led. (Tel Aviv, Israel), respectively. Recombinant soluble HA proteins from A/H5N1/Vietnam/1203/2004 (accession no. AAW80717.1) and A/H1N1/California/04/2009 (accession no. ACQ76318) were obtained from Prospec-Tany TechnoGene Led. (Tel Aviv, Israel). A/H3N2/ Panama/2007/1999 HA (accession no. ABH01004) was obtained from Immune Technology Corp. (NY, USA). All DNA oligos were chemically synthesized locally. The RNase inhibitor was from Life Technologies (USA). The biotinylated multivalent-glycans 01-088 [Neu5Aca2-3Galß1-3GalNAca1-PAA-biotin] and 01-000 $\left[\mathrm{HOCH}_{2}(\mathrm{HOCH})_{4} \mathrm{CH}_{2} \mathrm{NH}-\mathrm{PAA}\right.$-biotin] were obtained from GlycoTech (USA).

\subsection{Random RNA pool}


A library of RNAs with a central randomized sequence flanked by invariable 5' and 3' sequences was designed. The ssDNA library, consisting of TCTAATACGACTCACTATAGGAGCTCAGCCTTCACTGC-N74-GGCA CCACGGTCGGATCCTG DNAs with a contiguous 74-nucleotide random sequence, was synthesized. The random sequences were flanked by defined sequences, including the T7 promoter (in italics). The defined 5' and 3' sequences were 5'-TCTAATACGACTCACTATAGGAGCTCAGCCTTCACTGC-3' and 5'-CAGGA TCCGACCGTGGTGCC-3', respectively. Polymerase chain reaction (PCR) was performed with a random DNA library $\left(1 \times 10^{14}\right.$ molecules) with $0.25 \mu \mathrm{M}$ of each of the 5' and 3' primers. To preserve the abundance of the original library, the PCR was limited to eight cycles to avoid amplifying a skewed population from the random DNA library. The DNA library was converted into an RNA library by in vitro transcription using the T7 AmpliScribe kit (Epicentre Technologies, USA). This RNA library was used for selection.

\subsection{In vitro selection}

Selection was performed using $16 \mu \mathrm{g}\left(\sim 10^{14}\right.$ RNA molecules) of the original RNA library in RNA binding buffer (10 mM HEPES, pH 7.4; 150 mM NaCl) at a 22:1 molar ratio of RNA to protein. During the later selection cycles, the concentration of the recombinant hemagglutinin $(\mathrm{HA})$ from the A/H5N1/Vietnam/1203/2004 virus (native protein, accession no. AAW80717.1) was reduced to select high-affinity RNA molecules. The RNA was briefly heated to $95^{\circ} \mathrm{C}$ and then cooled to room temperature to form stable structures before the selection steps. In the selection cycles, tRNA (total tRNA from E. coli, Roche, Switzerland) was used as a nonspecific competitor. After the RNA was incubated 
with the HA protein from A/H5N1/Vietnam/1203/2004 at room temperature for 10 min, the protein-RNA complexes were filtered through a pre-wetted nitrocellulose acetate filter (HAWP filter, $0.45 \mu \mathrm{m}, 13.0-\mathrm{mm}$, Merck Millipore, USA) fitted in a "Pop-top" filter holder (Nucleopore) and washed with $1 \mathrm{ml}$ of binding buffer (10 mM HEPES, $\mathrm{pH} 7.4 ; 150 \mathrm{mM} \mathrm{NaCl}$ ). The RNAs that were retained on the filter were eluted and recovered as previously described $[26,27]$. The recovered RNAs were reverse-transcribed in $20 \mu \mathrm{l}$ of a reaction mixture containing $50 \mathrm{mM}$ Tris- $\mathrm{HCl}$ (pH 8.3), $50 \mathrm{mM} \mathrm{KCl}, 10 \mathrm{mM} \mathrm{MgCl}$, $0.5 \mathrm{mM}$ spermidine, $10 \mathrm{mM}$ DTT, $0.4 \mathrm{mM}$ dNTPs, $0.4 \mu \mathrm{M}$ primer and $25 \cup$ AMV reverse transcriptase (Wako, Japan). The nucleotides and enzymes were added after a denaturation and annealing step (2 min at $95^{\circ} \mathrm{C}$, followed by incubation at room temperature for $10 \mathrm{~min}$ ). Reverse transcription was performed for 45 min at $37^{\circ} \mathrm{C}$. The resulting cDNA was amplified by PCR and used as the template to obtain the RNA for the next round of selection. For amplification of the cDNA by PCR, a $20 \mu$ laliquot of the reverse transcription reaction (cDNA reaction mixture) was diluted in $80 \mu \mathrm{l}$ of PCR reaction mixture [PrimeSTAR Max Premix (Takara, Japan) and $1 \mu \mathrm{M}$ of each primer]. The cDNA was amplified using the following conditions: $95^{\circ} \mathrm{C}$ for $15 \mathrm{~s}$, $54^{\circ} \mathrm{C}$ for $10 \mathrm{~s}$, and $72^{\circ} \mathrm{C}$ for $10 \mathrm{~s}$. This program was repeated for as many cycles as needed to produce a DNA band of the correct size. The PCR product was precipitated in ethanol and used for transcription. In vitro transcription was performed at $37^{\circ} \mathrm{C}$ for $3 \mathrm{hr}$ with the T7 AmpliScribe kit (Epicentre Technologies). After treatment with DNase I, the reaction mixture was fractionated on an $8 \%$ denaturing polyacrylamide gel. The RNA was extracted from the gel, quantitated and used for the next cycle of selection and amplification. We manipulated each selection cycle to ensure the specificity and high affinity of the HA binders. For example, we modified the ratio of RNA to HA, the competitor concentration, and 
the buffer volume. To remove the filter binders, which increased the background, we used Xenobind plates for the $2^{\text {nd }}, 4^{\text {th }}, 6^{\text {th }}$, and $8^{\text {th }}$ rounds of selection (Table 1 ).

For the Xenobind selection steps, we initially coated the wells with $5 \mu \mathrm{g}$ of HA protein from A/H5N1/Vietnam/1203/2004 (native protein) per milliliter of binding buffer and blocked the remaining sites with BSA (3\% stock solution). The wells were then washed and used for selection. In the selection cycle, the RNA pool from the $1^{\text {st }}$ cycle was denatured at $95^{\circ} \mathrm{C}$ for 2 min and allowed to cool to room temperature for $10 \mathrm{~min}$ to facilitate the equilibration of the different conformers. Then, the pooled RNA $(1 \mu \mathrm{M})$ and tRNAs $(10 \mu \mathrm{M})$ were mixed in 60 $\mu \mathrm{l}$ of binding buffer and incubated for $10 \mathrm{~min}$ at room temperature $\left(25^{\circ} \mathrm{C}\right)$. The unbound RNAs were then collected and loaded into wells coated with HA. The reaction mixture was incubated in these wells for $10 \mathrm{~min}$. The unbound molecules were discarded, and the wells were washed with binding buffer (cycle 2: 2 times with $100 \mu$ l, cycle 4: 4 times with $100 \mu$, cycle 6: 10 times with $100 \mu$, and cycle 8: 10 times with $100 \mu \mathrm{l})$. The bound RNAs were recovered using a boiling $7 \mathrm{M}$ urea solution, precipitated with ethanol and regenerated by $\mathrm{RT}, \mathrm{PCR}$ and in vitro transcription.

\subsection{Binding analysis of aptamers}

To obtain individual aptamers, the amplified PCR products from cycle 10 were directly ligated into the pCRII vector (Invitrogen) according to the manufacturer's protocol. DNA was isolated from individual clones by the alkaline-lysis method and sequenced with the BigDye Terminator Sequencing kit (Life Technologies) on a DNA sequencer (Model 373A, Life Technologies). The secondary structures of the aptamers were predicted using the BayesFold program (version 1.01). To evaluate the HA binding of the RNA pools from 
selection cycle 8 and the individual aptamers, internally labeled RNA was prepared using $0.5 \mathrm{mCi} / \mathrm{ml}\left[\alpha^{32} \mathrm{P}\right] \mathrm{ATP}$, and binding studies were performed using a filter binding assay similar to that previously reported $[21,22,11]$. The binding and in vitro transcription conditions were similar to those used for selection, except for the RNA and HA protein concentrations. In this analysis, we used 20 nM labeled RNA and 100 or 200 nM HA protein derived from A/H5N1/Vietnam/1203/2004. The RNA-HA complexes retained on the filters were washed with $1 \mathrm{ml}$ of binding buffer and air dried, and the radioactivity was quantitated with an image analyzer (BAS2000, Fuji Film, Japan). To ensure that the binding was specific, we performed binding assays in the presence of a 10-fold molar excess of tRNA as a nonspecific competitor.

\subsection{Analyses of aptamer-HA interactions using surface plasmon resonance}

To evaluate the binding kinetics of the aptamer-HA interactions, we used a Biacore T100 optical biosensor at $25^{\circ} \mathrm{C}$ and a streptavidin-coated sensor chip (SA-chip, GE Healthcare, USA). To determine the binding rate constants of the selected aptamers, the aptamer's 3' end was extended with a 24-mer poly(A) tail, which could anneal to the complementary biotinylated oligo(dT) [5'-biotin-(T) $\left.{ }_{24}-3^{\prime}\right]$. To prepare this RNA with the 3' extension, we used two primers: a forward primer similar to that used in the selection and the reverse primer 5'-(T) 24 -CAGGATCCGACCGTGGTGCC-3'. The double-stranded DNA template was generated by PCR and transcribed in vitro as described above. To immobilize the aptamers, initially, the biotinylated oligo(dT) ${ }_{24}$ was allowed to bind to the streptavidin-coated surface (SA chip) by dissolving the oligo in binding buffer ( $5 \mu \mathrm{M}$ final concentration) and passing it through all four flow cells (FCs). The unbound biotinylated oligo was washed away with binding buffer at a flow 
rate of $20 \mu \mathrm{l} / \mathrm{min}$ for $10 \mathrm{~min}$. To hybridize aptamer 8-3 to the biotinylated oligo dT, $20 \mu \mathrm{l}$ of aptamer was injected (100 nM final concentration) into flow cell 2 at a flow rate of $2 \mu \mathrm{l} / \mathrm{min}$ for $10 \mathrm{~min}$. This resulted in an increase of approximately 1200 RU upon aptamer binding to the complementary biotinylated oligo. Similarly, aptamers 8-10 and 8-1 were hybridized in flow cell 3 and flow cell 4, respectively. Flow cell 1 was used as control. No aptamer was hybridized in the flow cell, but it contained the biotinylated oligo dT. Single-cycle kinetics were measured with various concentrations of HA protein from A/H5N1/Vietnam/1194/2004 (2.5, 5.0, $10,20$, or $40 \mathrm{nM})$ or $\mathrm{A} / \mathrm{H} 5 \mathrm{~N} 1 /$ Indonesia/05/2005 $(0.63,1.25,2.5,5.0$, or $10.0 \mathrm{nM})$ by injecting the protein through all flow cells (FC1-FC4) at a flow rate of $30 \mu \mathrm{l} / \mathrm{min}$ with a total volume of $60 \mu \mathrm{l}$. The dissociation time was set to 5 min to obtain a smooth curve. Sensorgrams were corrected for nonspecific binding by subtracting the control curve (FC1) from the aptamer-attached curve (FC2), and the binding kinetics were evaluated. Similarly, to analyze aptamers 8-10 and 8-1, we subtracted the response for FC1 from the responses for the aptamer-attached curves (FC2). All HA-aptamer binding data were analyzed using Biacore T100 Evaluation software, version 2.0.2 (GE Healthcare), and were fitted with a 1:1 binding model to estimate the association rate constant $(k a)$, dissociation rate constant $(k d)$, and equilibrium dissociation constant $\left(K_{D}\right)$. The sensor chip was then washed with a buffer solution, followed by injection of a $10 \mathrm{mM} \mathrm{NaOH}$ solution to strip the aptamer from the biotinylated (dT) ${ }_{24}$ before the next sample analysis. Similarly, we performed binding analyses for aptamer 8-3 with different HAs from other subtypes of influenza A virus: H1N1 (2.5 nM-40 nM), H3N2 (2.5 nM-40 nM), H7N7 (2.5 nM-40 nM), and H9N2 (2.5 nM-40 nM). Additionally, aptamer 8-3 was tested for binding to deglycosylated HAs after the HAs had been deglycosylated as previously described [25]. 


\subsection{Analysis of HA-glycan interactions}

A Biotin CAPture Kit (GE Healthcare) was used for this analysis as described previously $[29,30]$. The Sensor chip CAP enables the reversible capture of biotinylated ligands. Initially, the Biotin CAPture reagent, which is a modified form of streptavidin, was immobilized on the Sensor chip CAP for 5 min at a flow rate of $2 \mu \mathrm{l} / \mathrm{min}$. Next, to immobilize the biotinylated tetravalent glycan on the streptavidin-coated surface of the Sensor chip CAP, the glycans 01-000 and 01-088 [500 nM in 0.3 M sodium phosphate buffer $(\mathrm{pH}$ 7.4)] were injected for 3 to $7 \mathrm{~min}$ at a flow rate of $10 \mu \mathrm{l} / \mathrm{min}$. As a control, 01-000 was bound to the spacer and biotin, without the glycan. Once the glycan surface on the Sensor chip CAP had been prepared, different concentrations of recombinant A/H5N1/Indonesia/05/2005 hemagglutinin (HA) (ranging from 10-160 nM, native protein) were injected into the flow cells as the analyte at a flow rate of $30 \mu \mathrm{l} / \mathrm{min}$. For each analyte concentration, cycles of injecting the analyte for $120 \mathrm{~s}$ and 300 s, followed by dissociation and analyte-free buffer injection, were performed for 10 min. After each measurement, the sensor chip surface was regenerated by injecting a 3:1 mixture of regeneration stock 1 ( $8 \mathrm{M}$ guanidine hydrochloride) and regeneration stock $2(1 \mathrm{M} \mathrm{NaOH})$, as recommended by the manufacturer (GE Healthcare). The regeneration process uses the regeneration solution to remove the SA-biotin-multivalent glycan-HA complex. The HA-glycan binding data were analyzed using Biacore T100 Evaluation software, version 2.0.2 (GE Healthcare) and fitted with a 1:1 binding model to estimate the association rate constant $(k a)$, dissociation rate constant $(k d)$, and equilibrium dissociation constant $\left(K_{D}\right)$. 


\subsection{Analysis of HA-glycan interactions in the presence of aptamer 8-3}

To evaluate the ability of aptamer 8-3 to interfere with the HA-glycan interactions, we used the SPR-based assay described above. The biotinylated tetravalent-glycan 01-088 ( $\alpha 2-3$ glycan) was immobilized on the streptavidin-coated surface, as described above, in FC2, and glycan 01-000 (FC1) was used as a control. Once the surface had been prepared, we injected $80 \mathrm{nM}$ A/H5N1/Indonesia/05/2005 HA to obtain the initial response curve. Next, to determine the effect of aptamer 8-3 on the HA-glycan interactions, 80 nM HA was pre-incubated with different concentrations of aptamer $(0,25,50,100,200$ and $400 \mathrm{nM}$ ) at $25^{\circ} \mathrm{C}$ for $10 \mathrm{~min}$. Then, the complexes were injected through both the experimental flow cell (FC2) and the control flow cell (FC1) for 2 min at a flow rate of $30 \mu \mathrm{l} / \mathrm{min}$. The dissociation time was set to $2 \mathrm{~min}$. Sensorgrams were corrected for nonspecific binding by subtracting the response obtained for the control flow cell (FC1) from the response obtained for the glycan-immobilized (01-088) flow cell (FC2). The sensor chip was then regenerated as described above. The reduction in the response with increasing concentrations of aptamer was used to calculate the $\mathrm{EC}_{50}$ value using GraphPad Prism 5 as previously described [30].

2.8. Preparation of a smaller derivative of aptamer 8-3 and chemical modifications

To prepare a shorter variant of 8-3 RNA, we deleted nucleotides 1-48 and 92-113 using the DNA oligo 8-3S-template: 5'-TCTAATACGACTCACTATAGGGACAACCGCTGGAACTTGAAGTCGGTAA TGCGAGCGGAAAGCCC-3'; 8-3S-F: 5'-TCTAATACGACTCACTATAGGG-3'; and 8-3S-r: 5'-T(24) GGGCTTTCCGCTCGCATTACC-3', followed by PCR and in 
vitro transcription, as described above. The RNA for aptamer 8-3 was purified by 15\% PAGE and isolated as described for the full-length aptamer 8-3. Aptamer 8-3 and 8-3S were analyzed for binding to the HA of A/H5N1/Indonesia/05/2005 $(0.63,1.25,2.5,5.0,10.0 \mathrm{nM})$ using the SPR-based assay. Similarly, to prepare 2'-fluoro cytidine- and 2'-fluoro uridine-substituted aptamer 8-3, we used the same DNA template as that used to prepare aptamer 8-3 and performed in vitro transcription with the $\mathrm{T} 7$ DuraScribe kit (Epicentre Technologies) at $37^{\circ} \mathrm{C}$ in the presence of 2'F UTP, 2'OH CTP, 2'OH ATP and 2'OH GTP to generate 2'-fluoro-U aptamer 8-3S and in the presence of 2'OH UTP, 2'F CTP, 2'OH ATP and 2'OH GTP to generate 2'-fluoro-C aptamer 8-3S. The RNA was separated, purified and recovered by ethanol precipitation.

\section{Results}

\subsection{Selection of RNA ligands}

To select RNA aptamers that bind to the HA of HPAI H5N1, the starting RNA pool was randomized over a 74-nucleotide stretch flanked by a fixed 38-nucleotide primer region at the 5' end and a fixed 20-nucleotide primer region at the $3^{\prime}$ end. This randomized pool represented approximately $10^{14}$ different species under our experimental conditions, and these species were allowed to bind to the HA of HPAl H5N1 (A/H5N1/Vietnam/1203/2004; accession no. AAW80717.1). For the initial selection, the RNA pool and HA $(0.4 \mu \mathrm{M})$ were mixed and incubated for $10 \mathrm{~min}$ in the presence of buffering agents, and then, the free RNA was separated from the HA-RNA complexes by filtration or using Xenobind plates under the conditions required for the selection cycle. The bound RNAs were recovered in a hot $7 \mathrm{M}$ urea solution and subsequently amplified by 
reverse transcription, $\mathrm{PCR}$, and in vitro transcription. To select specific aptamers, competition between the individual sequences was allowed during the selection cycles. To allow competition, a high RNA pool-to-target protein ratio was used in the initial selection cycles. In the subsequent selection cycles, the ratio of the HA protein to RNA (pool RNA and tRNA) was manipulated to increase the selection stringency (Table 1). In addition, a nonspecific competitor, tRNA, was used at different molar ratios in the selection cycles to avoid the selection of aptamers with nonspecific binding. After 8 rounds of selection, both the enrichment for high-affinity HA-binding aptamers and their specificity were analyzed by filter binding assays. Approximately $36 \%$ of the RNA pool bound to HA (Table 1 ). No significant retention of the selected RNA pool occurred on the filter in the absence of $\mathrm{HA}$, indicating that nonspecific filter binders were not co-isolated during the course of selection. Two additional selection cycles were performed with more stringent conditions before the RNA pool was subcloned and sequenced. Individual aptamers from the tenth cycle were classified based on sequence similarity. After sequencing, we found that aptamer $8-3$ represented $43 \%$ of the population, whereas aptamers $8-1$ and $8-10$ represented $26 \%$ and $11 \%$, respectively, of the selected pool from cycle 10 (Fig. 1a). The primary sequences of these three aptamers were predicted and were found to have different secondary structures according to the BayesFold program (version 1.01) (Fig. 1b). All three aptamers were assayed to evaluate their ability to bind to native HA proteins derived from HPAl H5N1 (A/H5N1/Nietnam/1203/2004) at concentrations of 100 and $200 \mathrm{nM}$ in the presence of a 10-fold molar excess of tRNA to avoid nonspecific interactions with RNA. These filter binding assays showed that all three aptamers bind similarly to native HA from HPAI H5N1 (Fig. 1c). 


\subsection{Binding efficiency of the selected aptamers.}

To analyze the binding rate constants of selected aptamers (8-3, 8-1 and 8-10), we analyzed the binding of these aptamers to the HA of HPAI H5N1 (A/H5N1/Vietnam/1194/2004 and A/H5N1/Indonesia/05/2005) using a surface plasmon resonance-based assay (Biacore T100) as reported earlier [25-27]. In this analysis, single-cycle kinetics experiments were performed, which allowed us to inject continuously increasing concentrations of purified native HA protein from A/H5N1/Vietnam/1194/2004 $(2.5, \quad 5, \quad 10,20$ and $40 \mathrm{nM})$ or A/H5N1/Indonesia/05/2005 $(0.63,1.25,2.5,5$ and $10 \mathrm{nM})$ without regenerating the surface of the sensor chip (Fig. 2a). This type of analysis appears to be superior to multi-injection analyses $(31,32)$. These analyses allowed the calculation of the equilibrium dissociation constant $\left(K_{D}\right)$, the association rate constant $(k a)$ and the dissociation rate constant $(k d)$ for the binding of these three different aptamers to the HA derived from H5 influenza viruses (Tables 2-4). Our binding analyses indicate that aptamer 8-3 binds with equal affinity to the HAs derived from two important HPAI H5N1 variants, A/H5N1/Vietnam/1194/2004

$$
\text { (A/H5N1/Vietnam/1203/2004) }
$$

and A/H5N1/Indonesia/05/2005, in contrast to two other aptamers (8-1 and 8-10) that were co-selected during selection process. The binding of the aptamers to HA could be due to binding to either the glycans or amino acid residues of HA. To determine whether the aptamer binds to glycans or amino acids, we assessed the binding of aptamer 8-3 to both glycosylated (native protein) and deglycosylated HAs and found that the aptamer binding was not compromised (Table 2), suggesting that this aptamer recognizes specific amino acid residues of HA. 
3.3. Specificity of aptamer 8-3 for the HAs of different subtypes of influenza A virus

To determine the specificity of aptamer 8-3 and its ability to discriminate HAs from other subtypes of influenza A virus, we again used the SPR-based binding assay with the Biacore T100 system, as mentioned above. We analyzed the kinetics of the binding of aptamer 8-3 to the HAs from the A/H1N1/California/04/2009, A/H3N2/Panama/2007/1999, A/H7N7/Netherlands /219/2003, A/H9N2/Hong Kong/1073/99, A/H5N1/Vietnam/1194/2004 and A/H5N1/Indonesia/05/2005 influenza viruses (Tables 2-4). These analyses showed that aptamer 8-3 bound efficiently to the HAs derived from A/H5N1/Indonesia/05/2005, A/H5N1/Vietnam/1194/2004, and A/H7N7/Netherlands/219/2003 and bound weakly to HAs of other subtypes of influenza A virus. Aptamer 8-3 bound to the HAs derived from A/H1N1/California/04/2009 and A/H9N2/Hong Kong/1073/99 1000-fold less efficiently than to the HAs of A/H5N1/Indonesia/05/2005 and A/H5N1/Vietnam/1194/2004, and this aptamer failed to bind to the HA from the A/H3N2/Panama/2007/1999 virus (Table 2).

Similarly, aptamers 8-1 and 8-10 were able to bind more efficiently to the H5N1 HAs and H7N7 HAs than to the HAs from H9, $\mathrm{H} 1$ and $\mathrm{H} 3$ viruses (Tables 3-4). These binding analyses suggest that aptamer 8-3 is able to single out HAs derived from $\mathrm{H} 1, \mathrm{H} 3$, and $\mathrm{H} 9$ viruses. However, accurate rate constants were not obtained for some aptamers due to their poor ability to bind to different HAs derived from other subtypes of influenza A virus.

\subsection{Aptamer 8-3 interferes with HA-glycan interactions}


Next, aptamer 8-3 was evaluated to determine its ability to interfere with HA-glycan interactions. For this analysis, we used our previously established SPR-based methodology to analyze the HA-glycan interactions $[28,29]$. In this assay, we immobilized tetravalent glycans ( $\alpha 2-3$ glycans and/or $\alpha 2-6$ glycans) on the SA surface and then passed HA over this surface. Upon HA binding, a response is generated corresponding to the bound mass. Our analyses, in previous studies and the current study [28; Fig. 3a], showed that the HAs from A/H5N1/Vietnam/1194/2004 and A/H5N1/Indonesia/05/2005 bind to $\alpha 2-3$ glycans with sub-nanomolar affinities (equilibrium dissociation constant $K_{D}$ between 4 and $14 \mathrm{nM}$ ), and no binding was observed for $\alpha 2-6$ glycans. However, Sauter et al [33] reported lower affinities between the HA derived from H3N2 and the glycans. This could be due to differences in HAs affinities to the glycans among subtypes or experimental techniques used and their sensitivities. Because our studies clearly revealed that the HA of $\mathrm{H} 5 \mathrm{~N} 1$ binds efficiently to a2-3 glycans, we used in the present competitive assay to block this interaction by the selected aptamer. A schematic representation of the competitive assay is shown in figure 3b. In this assay, a multivalent $\alpha 2-3$ glycan (Neu5Aca2-3Galß1-3GalNAca1-PAA-biotin) was immobilized on the streptavidin surface (SA) after capture of the SA-containing reagent on the Sensor chip CAP (GE Healthcare). The initial binding response was recorded using $80 \mathrm{nM}$ of HA protein from $\mathrm{A} / \mathrm{H} 5 \mathrm{~N} 1 /$ Indonesia/05/2005. We assumed that this response would decrease if the HA was bound by aptamer 8-3. The above aptamer binding analyses suggested that the selected aptamer (8-3) binds to HA proteins derived from A/H5N1/Vietnam/1194/2004 (A/H5N1/Vietnam/1203/2004) and $\mathrm{A} / \mathrm{H} 5 \mathrm{~N} 1 /$ Indonesia/05/2005. For the competition binding analyses, we mixed different concentrations $(25,50,100,200$, and 400 nM) of aptamer 8-3 with the 
HA of A/H5N1/Indonesia/05/2005 (17 response units) and incubated this mixture for 1 hour before passing it over the glycan surface. We observed that with increasing aptamer concentrations, the binding of HA to the glycan surface decreased. Using these response signals, the effector concentration of aptamer 8-3 necessary for $50 \%$ inhibition $\left(E_{50}\right)$ of the HA-glycan interactions was calculated, and it was found to be in the nanomolar range $\left(\mathrm{EC}_{50} \sim 25 \mathrm{nM}\right)$ (Fig. 3c). These analyses suggest that the binding of this aptamer to HA interferes efficiently with the HA-glycan interactions. However, a complementary sequence failed to reduce the HA-glycan interactions (data not shown).

\subsection{Preparation of a shorter version of aptamer 8-3}

The length of aptamer 8-3 is 113 nucleotides, and to make this aptamer more suitable for various applications, it is important to reduce its length to approximately 40 nucleotides. To reduce the aptamer's length, we have performed deletion analyses using full-length aptamer 8-3 and found that an aptamer that contains nucleotides $48-92$ is able to bind efficiently to the HA of A/H5N1/Indonesia/05/2005 (Fig. 4a\&b). The binding efficiency was similar to that of the full-length aptamer, suggesting that all of the functional groups of the RNA that are important for $\mathrm{HA}$ binding are present in the shorter derivative aptamer 8-3S (Fig. 4a\&b). We next explored the incorporation of 2'-fluoro modifications to improve the stability of the aptamer in the presence of endo-ribonucleases. We modified only pyrimidine residues in aptamer 8-3S, as these sites are known to be sensitive to endo-ribonucleases. We prepared two types of aptamers, one in which all cytidine residues were replaced with 2'-fluoro-C and another in which all uridine residues were replaced with 2'-fluoro-U, using an in vitro transcription process (Fig. 5a). These two RNAs 
were prepared with a 24-mer poly(A) tail (adenosine) at their 3' ends, which can be hybridized to biotinylated $\mathrm{dT}_{(24)}$ for the SPR-based binding analyses. The binding of these aptamers to the $\mathrm{HA}$ of $\mathrm{A} / \mathrm{H} 5 \mathrm{~N} 1 /$ Indonesia/05/2005 was assessed in a manner similar to that described for the shorter and full-length aptamer binding studies using the SPR-based method. The binding analyses revealed that when all cytidine residues in the shorter variant 8-3S were replaced with 2'-fluoro-C, the binding efficiency was not affected, whereas when all uridine residues were modified, the binding efficiency was reduced by approximately 400-fold (Fig. 5b). After we partially stabilized aptamer 8-3S, we tested the 2'-fluoro-C variant for its ability to interfere with the HA-glycan interactions using the SPR-based method described above. The analyses revealed that the 2'-fluoro-C-modified shorter aptamer retained the ability to interfere with the HA-glycan interactions as efficiently as unmodified aptamer 8-3S $\left(\mathrm{EC}_{50} \sim 18 \mathrm{nM}\right)$ (Fig. 6a). These results suggest that aptamer 8-3S represents a shorter aptamer that retains high affinity for the HAs from A/H5N1/Indonesia/05/2005 and A/H5N1/Vietnam/1194/2004 and interferes efficiently with the HA-glycan interactions. Because the modified aptamer 8-3S binds to the HAs of A/H5N1/Indonesia/05/2005 and A/H7N7/Netherlands/219/2003, we also tested this aptamer's ability to interfere with glycan binding (Fig. 6b). Our analyses show that this aptamer is able to interfere with glycan binding, albeit less efficiently than for the binding of glycans to the HAs of $\mathrm{A} / \mathrm{H} 5 \mathrm{~N} 1$ viruses (Fig. 6b). Thus, it was difficult to estimate the effector concentrations.

\section{Discussion}

Currently, the HPAI H5N1 virus is panzootic in avian populations but 
continues to pose major challenges to the poultry industry worldwide. Although H5N1 viruses are not pandemic viruses, these viruses are continuously evolving, and over the past two decades, the frequency of H5N1 outbreaks has increased. The 2003 H5N1 virus infects humans, and human infections have been reported in 15 countries [34]. Thus, HPAI H5N1 viruses appear to have the potential become pandemic-type viruses. If we accept this hypothesis, then it is important to have contingency plans to contain or minimize the damage if an H5N1 pandemic occurs. Recently, Rappuoli and Dormitzer [35] suggested that the contingency plans should include the early detection and surveillance of HPAI H5N1 viruses to facilitate responding to pandemic influenza viruses. As exemplified in recent article by Butler, influenza surveillance is poor in countries affected by H5N1 [36]. Some of these issues stem from the absence of efficient and specific reagents for detecting HPAl viruses such as H5N1 and H7N7. To develop such reagents, in the present study, we isolated an aptamer (8-3) that binds efficiently to A/H5N1/Vietnam/1194/2004 and A/H5N1/Indonesia/05/2005, with equilibrium dissociation constants in the picomolar range. Aptamer 8-3 appears to bind to the HAs of H5N1 clade 1 and clade 2 (sub-class 1 ), as the above viruses belong to these classes. Next, aptamer 8-3 was tested for its ability to bind to other HA subtypes, such as those of H1N1, H3N2, H7N7, and H9N2 viruses. Aptamer 8-3 binds with greater specificity to H5N1 and H7N7 HAs and with lower specificity to the HAs of other subtypes of influenza virus. Two other selected aptamers (8-1 and 8-10) also bound similarly to their cognate HAs (derived from $\mathrm{H} 5$ and $\mathrm{H} 7$ viruses) but with lower affinities. All these analyses suggest that among the three selected aptamers, aptamer 8-3 is best able to distinguish these two HAs of $\mathrm{H} 5$ and $\mathrm{H} 7$ viruses from other HAs. Interestingly these two viruses H5N1 and H7N7 are classified as HPAI. 
These two viruses have multi-basic cleavage site that are cleaved by furin-like proteases. This region is located between the HA1 and HA2 subunits, which facilitate processing of $\mathrm{HAO}$ (uncleaved form) into the HA1 and HA2 subunits to mediate efficient membrane fusion. Interestingly, all major HPAI strains possess multi-basic cleavage site (consisting of multiple arginine and lysine residues) between the HA1 and HA2 subunits and lack carbohydrate residues near this cleavage site $[19,20]$. To determine whether the selected aptamer (8-3) is able to bind variants that lack the multi-basic cleavage site, we carried out binding assays using SPR. These analyses show that aptamer (8-3) specifically binds to the HAs derived from $\mathrm{H} 5 \mathrm{~N} 1$ and $\mathrm{H} 7 \mathrm{~N} 7$ viruses possessing the readily cleavable region and lost its binding to the HAs (derived from H5N1 and H7N7 viruses) that were deleted this region (Fig. 7a\&b). Previously, we reported two aptamers, P30-10-16 and D-26, that bind specifically to the HAs of H3N2 and H1N1 viruses, respectively. These aptamers displayed similar specificity toward their cognate HAs and were able discriminate other subtypes of influenza A virus $[25,27]$.

To make aptamer 8-3 more suitable for various applications in influenza diagnosis and surveillance and for the development of topical virucidal products, it is important to reduce its length from 113 nucleotides to approximately 40 nucleotides. To reach this goal, we performed deletion analyses and found that the region of nucleotides 48-92 (44-mer) was sufficient for efficient binding, with a binding affinity similar to that of the full-length aptamer (Fig. 4b). Aptamer 8-3S is a shorter aptamer that binds as efficiently as the full-length aptamer, 8-3, and also inhibits HA-glycan interactions. To improve the aptamer's stability in the presence of endo-ribonucleases, we substituted the pyrimidines in the shorter aptamer, 8-3S, with 2'-fluoro pyrimidines. We observed that all cytidine residues 
could be substituted with 2'-fluoro cytidine without compromising the binding to HA, whereas the substitution of the uridine residues with 2'-fluoro uridine affected the binding affinity, suggesting that some of these uridines play important roles in the binding to HA (Fig. 5b). Next, we determined whether the binding of the H5N1 HA to glycans is affected by the presence of aptamer 8-3 using the SPR-based assay. These analyses indicated that the aptamer effectively interferes with HA-glycan binding, with $\mathrm{EC}_{50}$ values of $\sim 25 \mathrm{nM}$ and $\sim 18 \mathrm{nM}$ for the full-length and shorter variants of aptamer 8-3, respectively (Fig. 3c and 6a). However, although aptamer 8-3 can bind to the HA of A/H7N7/Netherlands/219/2003, this aptamer was found to interfere only weakly with the HA-glycan interactions when using this HA (Fig. 6b). Structural analysis of the aptamer-HA complex may reveal the binding site and shed light on how these aptamers interfere with HA-glycan interactions.

In summary, the present study identified an aptamer (8-3) that binds with high affinity to the HAs of HPAI H5N1 and H7N7 viruses and is able to distinguish other subtypes of influenza viruses. Importantly, aptamer 8-3 and its shorter version (8-3S) efficiently interfere with HA-glycan interactions. We believe that this aptamer (8-3S) has applications not only in the diagnosis and surveillance of H5N1 and H7N7 viruses but also in the development of H5N1and H7N7-specific virucidal products that interfere with the initial virus-host interactions. Thus, this aptamer may play a role in containing future $\mathrm{H} 5 \mathrm{~N} 1$ and H7N7 pandemics.

\section{Acknowledgments}


This work was supported by JST grants awarded to Dr. Penmetcha Kumar. The authors would like to thank Drs. Subash S.C. Gopinath and Hiroshi Mizuno for useful discussion.

\section{References}

[1] WHO. A revision of the system of nomenclature for influenza viruses: a WHO Memorandum. Bull. 1980; 58: 585-591.

[2] Webster RG, Bean WJ, Gorman OT, Chamebrs TM, Kawaoka Y. Evolution and ecology of influenza A viruses. Microbiol. Rev. 1992; 56:152-179

[3] Horimoto T, Kawaoka Y. Influenza: lessons from past pandemics, warnings from current incidents. Nat. Rev. Microbiol. 2005; 3: 591-600.

[4] Skehel JJ, Wiley DC. Receptor binding and membrane fusion in virus entry: the influenza haemagglutinin. Annu. Rev. Biochem. 2000; 69: 531-569.

[5] Russell RJ, Stevens DJ, Haire LF, Gamblin SJ, Skehel JJ. Avian and human receptor binding by haemagglutinins of influenza A viruses. Glycoconj. J. 2006; 23: 85-92.

[6] Shinya K, Ebina M, Yamada S, Ono M, Kasai N, Kawaoka Y. Avian flu: influenza virus receptors in the human airway. Nature 2006; 440: 435-436.

[7] Matrosovich M, Tuzikov A, Bovin N, Gambaryan A, Klimov A, Castrucci MR, Donatelli I, Kawaoka Y. Early alterations of the receptor-binding properties of $\mathrm{H} 1, \mathrm{H} 2$, and $\mathrm{H} 3$ avian influenza virus haemagglutinins after their introduction into mammals. J. Virol. 2000; 74: 8502-8512.

[8] Hampson AW. Influenza virus antigens and 'antigenic drift'. In: Potter CW, editor. Influenza. Amsterdam: Elsevier Science 2002, p. 49-85.

[9] Webster RG, Kendal AP, Gerhard W. Analysis of antigenic drift in recently isolated influenza $A(\mathrm{H} 1 \mathrm{~N} 1)$ viruses using monoclonal antibody preparations. Virology 1979; 96: 258-264.

[10] Webster RG, Wright SM, Castrucci MR, Bean WJ, Kawaoka Y. Influenza-a model of an emerging virus disease. Intervirology 1993; 35: 16-25.

[11] Kawaoka Y, Krauss S, Webster RG. Avian-to-human transmission of the PB1 gene of influenza A viruses in the 1957 and 1968 pandemics. J Virol. 1989; 63: 4603-4608.

[12] Garten RJ, Davis CT, Russell CA, Shu B, Lindstrom S, Balish A. Antigenic and genetic characteristics of swine-origin 2009 A(H1N1) influenza viruses circulating in humans. Science 2009; 325: 197-201. 
[13] Scholtissek C, Rohde W, Von Hoyningen V, Rott R. On the origin of the human influenza virus subtypes H2N2 and H3N2. Virology 1978; 87: 13-20.

[14] Kawaoka Y, Bean WJ, Webster RG. Evolution of the haemagglutinin of equine H3 influenza viruses. Virology 1989; 169: 283-292.

[15] De Jong JC, Claas EC, Osterhaus AD, Webster RG, Lim WL. A pandemic warning?. Nature 1997; 389: 554.

[16] Taubenberger JK, Morens DM, Fauci AS. The next influenza pandemic: can it be predicted?. JAMA 2007; 297: 2025-2027.

[17] Imai M, Kawaoka Y. The role of receptor binding specificity in interspecies transmission of influenza viruses. Current Opinion in Virology 2012; 2: 1-8.

[18] Bosch FX, Garten W, Klenk H.-D, Rott R. Proteolytic cleavage of influenza virus hemagglutinins: primary structure of the connecting peptide between HA1 and HA2 determines proteolytic cleavability and pathogenicity of avian influenza viruses. Virology 1981; 113: 725-735.

[19] Desphande KL, Fried VA, Ando M, Webster RG. Glycosylation affects cleavage of an H5N2 influenza virus hemagglutinin and regulates virulence. Proc. Natl. Acad. Sci. USA 1987; 84: 36-40.

[20] Kawaoka Y, Webster RG. Interplay between carbohydrate in the stalk and the length of the connecting peptide determines the cleavability of influenza virus hemagglutinin. J. Virol. 1989; 63: 3296-3300.

[21] Horimoto T, Kawaoka Y. Pandemic Threat Posed by Avian Influenza A Viruses. Clin. Microbiol. Rev. 2001; 14: 129-149.

[22] Claas EC, Osterhaus AD, van Beek R, De Jong JC, Rimmelzwaan GF, Senne DA, Krauss S, Shortridge KF, Webster RG. Human influenza A H5N1 virus related to a highly pathogenic avian influenza virus. Lancet 1998; 351: 472-477.

[23] Subbarao K, Klimov A, Katz J, Regnery H, Lim W, Hall H, Perdue M, Swayne D, Bender C, Huang J, Hemphill M, Rowe T, Sahw M, Xu X, Fukuda K, Cox N. Characterization of an avian influenza A (H5N1) virus isolated from a child with a fatal respiratory illness. Science 1998; 279: 393-396.

[24] Vijaykrishna D, Bahl J, Riley S, Duan L, Zhang JX, Chen H, Peiris JS, Smith GJ, Guan Y. Evolutionary dynamics and emergence of panzootic H5N1 influenza viruses. PLoS Pathog. 2008; 4: e1000161.

[25] Gopinath SCB, Misono T, Kawasaki K, Mizuno T, Imai M, Odagiri T, and Kumar PKR. An RNA aptamer that distinguishes between closely related 
human influenza viruses and inhibits hemagglutinin-mediated membrane fusion. J. Gen. Virology 2006; 87: 479-487.

[26] Gopinath SCB, Yuriko S, Kawasaki K, Kumar PKR. Selection of anti-influenza $B$ aptamer that binds to $H A$ and inhibit efficiently. J. Biochemistry 2006; 139: 837-846.

[27] Gopinath SCB, Kumar PKR. Aptamers that bind to the hemagglutinin of the recent pandemic $\mathrm{H} 1 \mathrm{~N} 1$ and efficiently inhibit the agglutination. Acta Biomaterialia 2013; 9: 8932-8941.

[28] Suenaga E, Mizuno H, Kumar PKR, Monitoring influenza hemagglutinin and glycan interactions using surface plasmon resonance. Biosensors and Bioelectronics 2012; 32: 195-201.

[29] Suenaga E, Mizuno H, Kumar PKR. Influenza virus surveillance using surface plasmon resonance. Virulence 2012; 3: 464-470.

[30] Gopinath SCB, Hayashi K, Kumar PKR. Aptamer that binds to the gD protein of herpes simplex virus-1 and efficiently inhibits viral entry. J. Virology 2012; 86: 6732-6744.

[31] Karlsson R, Katsamba PS, Nordin H, Pol E, Myszka DG. Analyzing a kinetic titration series using affinity biosensors. Anal.Biochem. 2006; 349: 136-147.

[32] Trutnau HH, New multi-step kinetics using common affinity biosensors saves time and sample at full access to kinetics and concentration. J. Biotechnol. 2006; 124: 191-195.

[33] Sauter NK, Bednarski MD, Wurzburg BA, Hanson JE, Whitesides GM, Skehel JJ, Wiley DC. Hemagglutinins from two influenza variants bind to sialic derivatives with millimolar dissociation constants: a $500-\mathrm{MHz}$ proton nuclear magnetic resonance study. Biochemistry 1989; 28: 8388-8396.

[34] World Health Organization. 12 March (2013) World Health Organization, Geneva, Swizerland. http://www.who.int/influenza/human_ animal_interface/H5N1_cumulative_table_archives/en/.

[35] Rappuoli R, Dormitzer PR. Influenza: options to improve pandemic preparation. Science 2012; 336: 1531-1533.

[36] Butler D. Flue surveillance lacking. Nature 2012; 483: 520-522. 


\section{FIGURE LEGENDS}

Fig. 1

In vitro-selected aptamers and their abilities to bind to the HA of A/H5N1/Vietnam/1203/2004. a) Nucleotide sequences of the predominant aptamers found in the selected pool from cycle 10. The underlined sequences emerged from the randomized region of the RNA pool, and their representation in the selected pool is shown as a percentage. b) The predicted secondary structures of aptamers 8-3, 8-1 and 8-10 are presented (BayesFold, version 1.01). c) Filter binding assays were performed with labeled aptamers in the presence of native HA (100 and $200 \mathrm{nM}$ ) from A/H5N1/Vietnam/1203/2004, and tRNA was used as a nonspecific competitor.

Fig. 2

A single-cycle binding kinetics were measured with aptamer 8-3 in the presence of various concentrations of HA proteins $(0.63,1.25,2.5,5.0,10.0,20.0$, and $40.0 \mathrm{nM}$ ) derived from the A/H5N1/Vietnam/1194/2004 (native) and A/H5N1/Indonesia/05/2005 influenza viruses.

Fig. 3

Analysis of HA-glycan interactions and interference by selected aptamers using SPR. a) Rate constants (association rate constant $\left(k_{\mathrm{a}}\right)$, dissociation rate constant $\left(k_{\mathrm{d}}\right)$ and equilibrium dissociation constant $\left(K_{\mathrm{D}}\right)$ for each of HA-synthetic glycan complexes using HAs derived from HPAl viruses (A/H5N1/Indonesia/05/2005 and A/H7N7/Netherlands/219/2003). b) A schematic representation of the experiments used to analyze the ability of 
aptamers to interfere with HA-glycan interactions using SPR. c) The ability of the aptamer to interfere with the interaction between the HA of A/H5N1/Indonesia/05/2005 and glycans. The observed responses for each concentration of aptamer 8-3 $(25,50,100,200$, and $400 \mathrm{nM})$ were plotted, and the $\mathrm{EC}_{50}$ was estimated.

Fig. 4

The shorter aptamer 8-3 (8-3S) and its ability to bind to the HA derived from the A/H5N1/Indonesia/05/2005 virus. a) Predicted secondary structure of aptamer 8-3 after truncation of the full-length aptamer 8-3. The truncated regions are circled with blue dotted lines. b) Single-cycle binding kinetics for the full-length aptamer and the shorter aptamer 8-3S in the presence of various concentrations of $\mathrm{HA}(0.63,1.25,2.5,5.0$ and $10.0 \mathrm{nM})$. All rate constants for aptamers 8-3 and 8-3S are shown in the table.

Fig. 5

Incorporation of modified nucleotides into the shorter aptamer 8-3S and the effects on the binding of the aptamer to the HA derived from the A/H5N1/Indonesia/05/2005 virus. a) The secondary structure of the shorter aptamer 8-3S is shown, and the modified nucleotides are indicated by blue and red letters for 2'-fluoro-U and 2'-fluoro-C, respectively. b) A single-cycle binding assay with 8-3S and 2'-fluoro-modified aptamers in the presence of various concentrations of HA $(0.63,1.25,2.5,5.0$ and $10.0 \mathrm{nM})$.

Fig. 6 
Analysis of the ability of aptamer 8-3 to interfere with HA-glycan interactions using SPR. a) Interference of aptamer 8-3S (modified with 2'-fluoro-C) with the interaction between the $\mathrm{HA}$ of $\mathrm{A} / \mathrm{H} 5 \mathrm{~N} 1 /$ Indonesia/05/2005 and glycans. The observed responses for each concentration of 2'-fluoro-C-modified aptamer 8-3S $(25,50,100,200$, and $400 \mathrm{nM})$ were plotted, and the $\mathrm{EC}_{50}$ was estimated. b) Interference of aptamer 8-3S (2'-fluoro-C) with the interaction between the HA of $\mathrm{A} / \mathrm{H} 7 \mathrm{~N} 7 /$ Netherlands/219/2003 and glycans. The observed responses for each concentration of 2'-fluoro-C-modified aptamer 8-3S (25, 50, 100, 200, and $400 \mathrm{nM}$ ) are depicted as bar diagrams.

\section{Fig. 7}

A single-cycle binding kinetics were measured with aptamer 8-3 in the presence of various concentrations of HA proteins $(2.5,5.0,10.0,20.0$, and $40.0 \mathrm{nM})$ derived from the A/H5N1/Vietnam/1194/2004 and A/H7N7/Netherlands/219/2003 influenza viruses. a) A/H5N1/Vietnam/1194/2004 (native HA protein) and A/H5N1/Vietnam/1194/2004 (cleavage site residues deleted variant HA protein). Cleavage site region was highlighted in box with arrow indicting cleavage site. b) A/H7N7/Netherlands/219/2003 (native HA protein) and A/H7N7/Netherlands/219/2003 (cleavage site residues deleted variant HA protein). Cleavage site region was highlighted in box with arrow indicting cleavage site. 


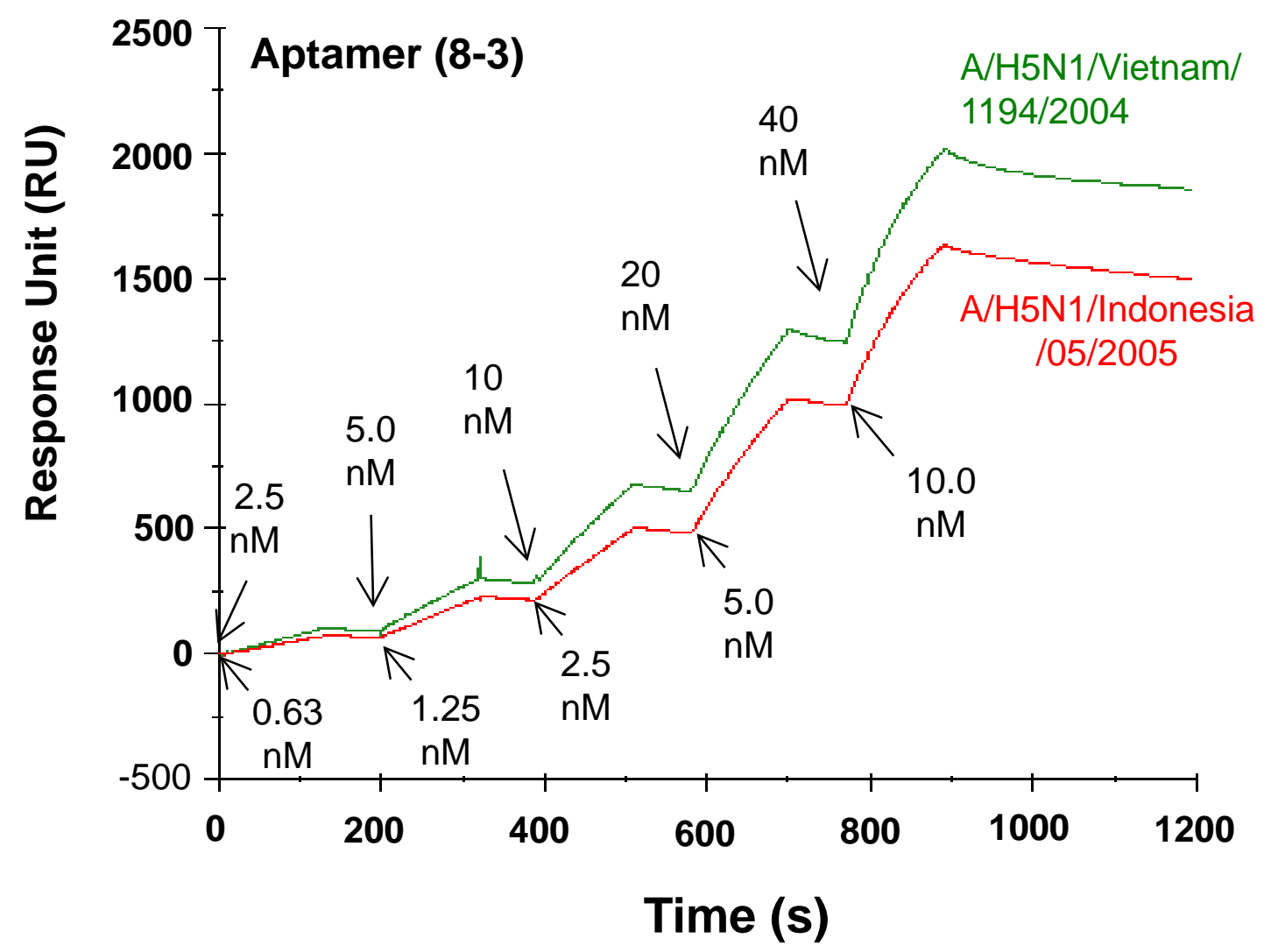

Fig. 2 


\begin{tabular}{|l|l|l|c|c|}
\hline $\mathbf{a}$ & & $\begin{array}{c}\text { Association } \\
\text { constant (ka) } \\
(1 / \mathrm{Ms})\end{array}$ & $\begin{array}{c}\text { Dissociation } \\
\text { constant (kd) } \\
(1 / \mathrm{s})\end{array}$ & $\begin{array}{c}\text { Equilibrium Dissociation } \\
\text { constant (KD) } \\
(\mathrm{M})\end{array}$ \\
\cline { 2 - 5 } $01-088$ & $\begin{array}{l}\mathrm{A} / \mathrm{H} 5 \mathrm{~N} 1 / \text { Indonesia } \\
/ 05 / 2005\end{array}$ & $1.9 \times 10^{5}$ & $2.7 \times 10^{-3}$ & $1.4 \times 10^{-8}$ \\
\cline { 2 - 5 } & $\begin{array}{l}\mathrm{A} / \mathrm{H} 7 \mathrm{~N} 7 / \mathrm{Netherlands} \\
/ 219 / 2003\end{array}$ & $7.9 \times 10^{4}$ & $3.7 \times 10^{-4}$ & $4.7 \times 10^{-9}$ \\
\hline
\end{tabular}

b

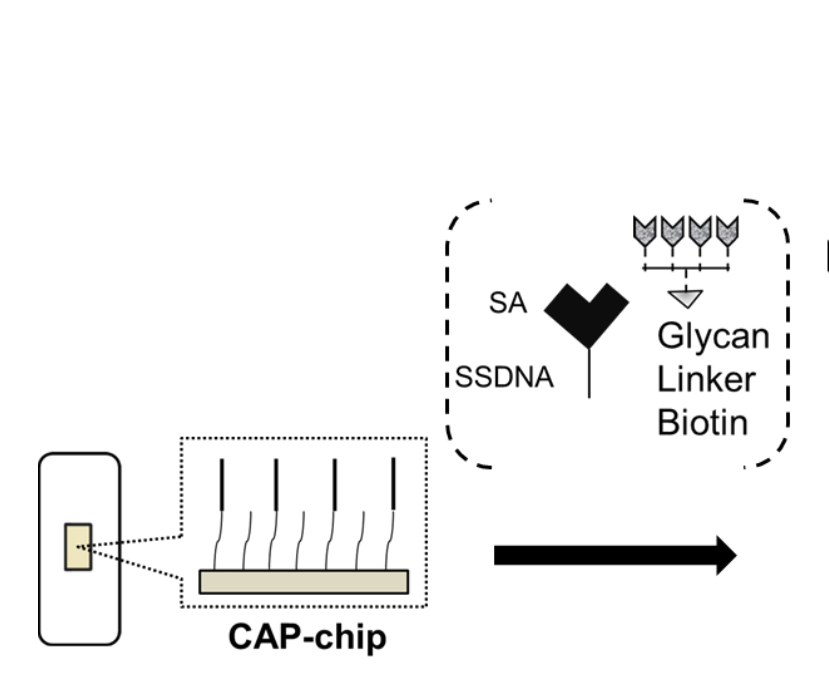

Optamer
HA

Fig. $3 a \& b$

Tetravalent $\alpha 2-3$

Glycan surface

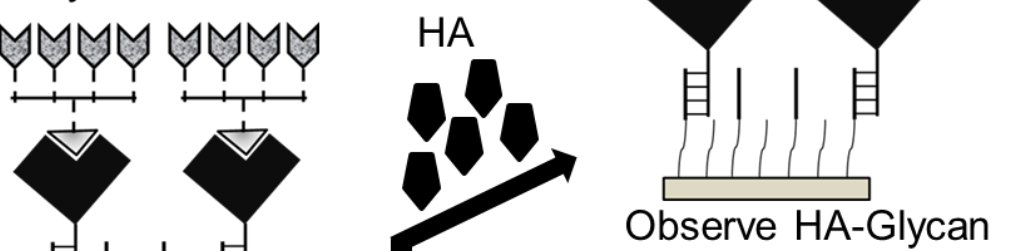

Binding response in SPR
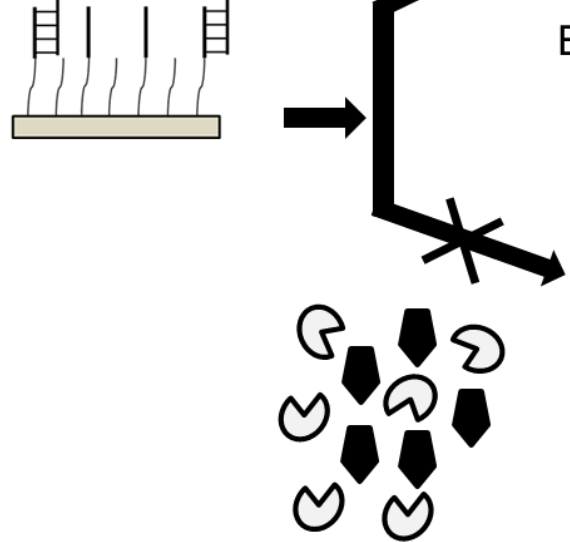

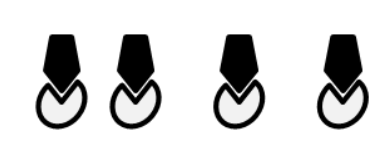

MMMM MMMM

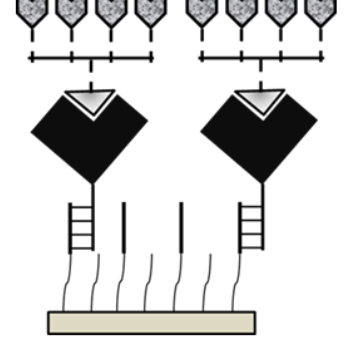

Reduced/ Lost Binding response with increasing aptamer concentrations 


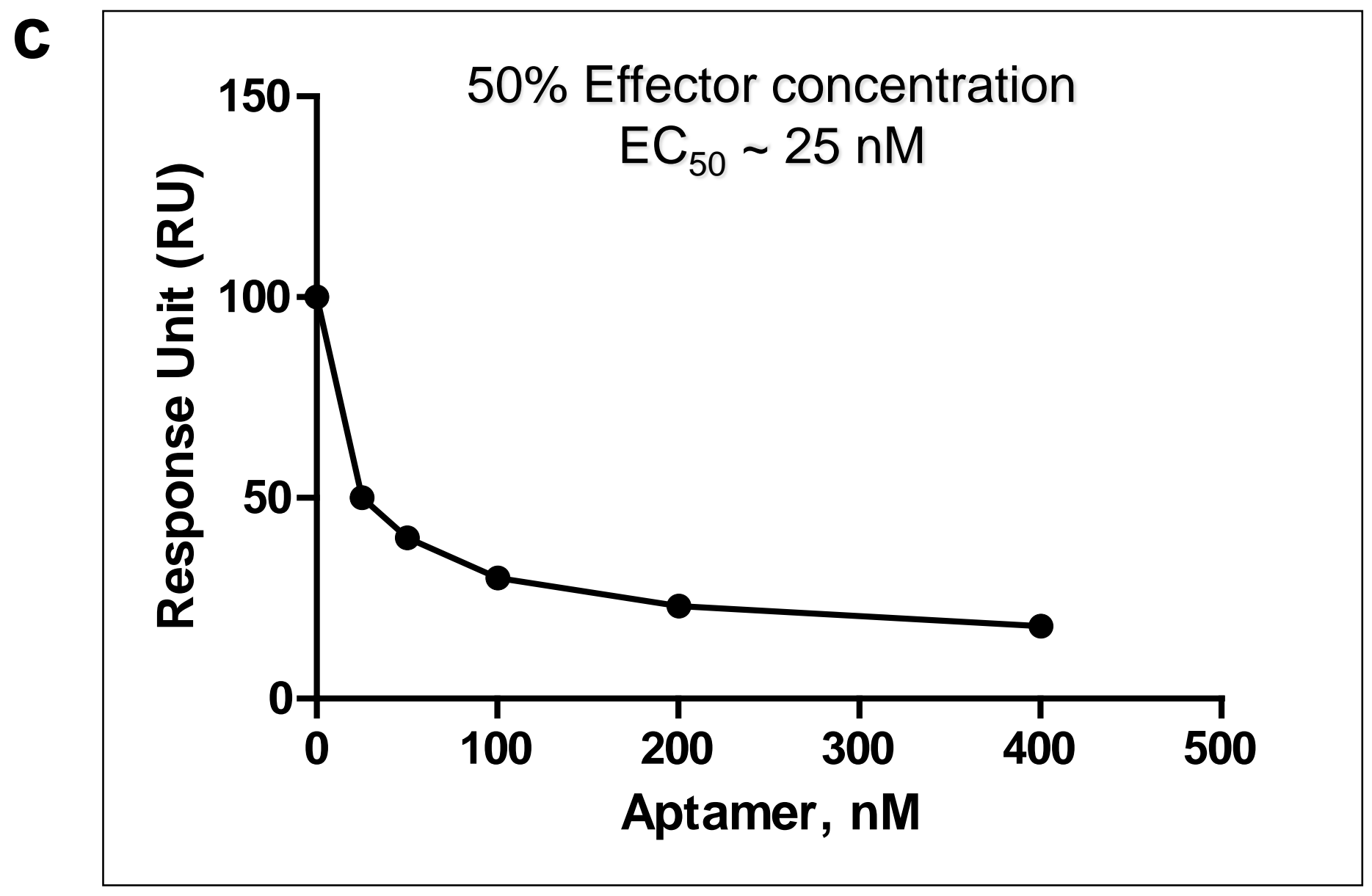

Fig. 3c 
a

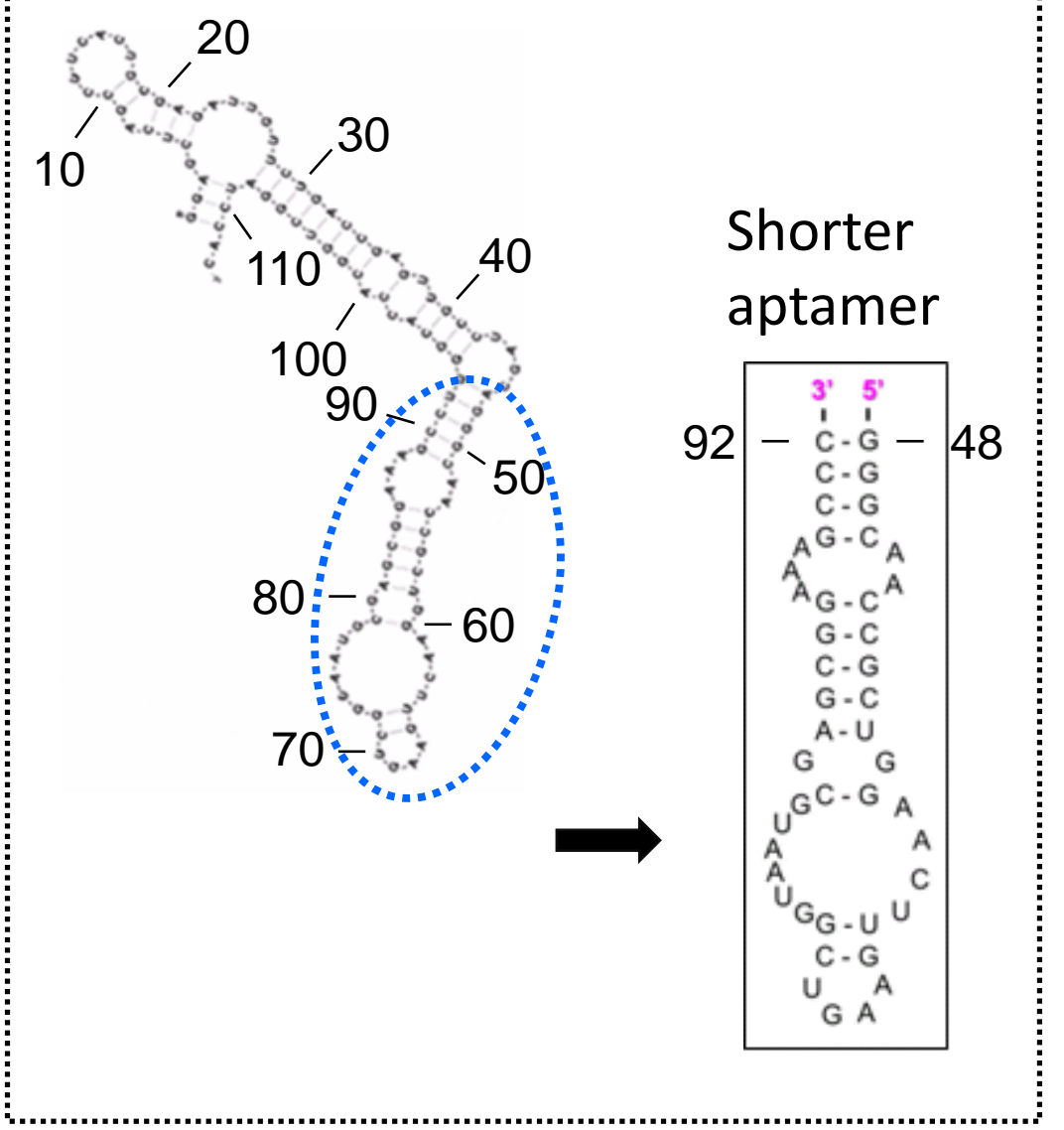

b

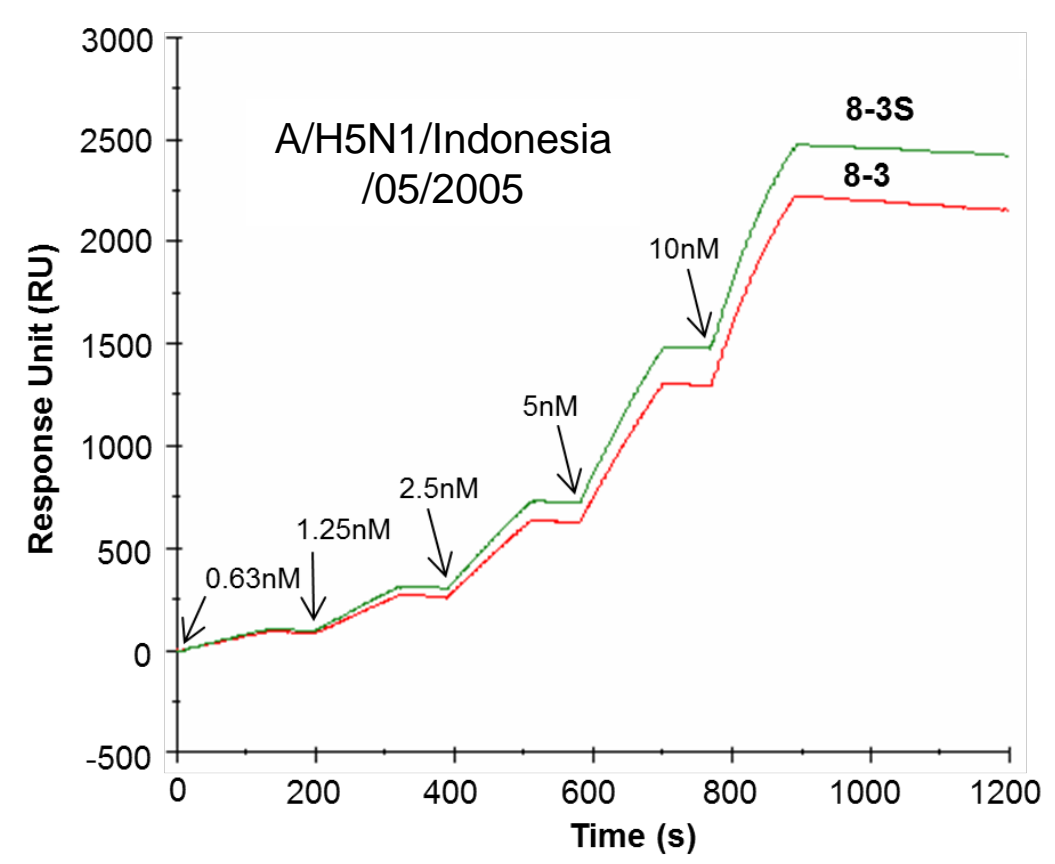

\begin{tabular}{|l|ccc|}
\hline & $\begin{array}{c}\text { Association } \\
\text { constant (ka) } \\
(1 / \mathrm{Ms})\end{array}$ & $\begin{array}{c}\text { Dissociation } \\
\text { constant (kd) } \\
(1 / \mathrm{s})\end{array}$ & $\begin{array}{c}\text { Equilibrium Dissociation } \\
\text { constant (KD) } \\
(\mathrm{M})\end{array}$ \\
\cline { 2 - 4 } $8-3$ & $8.4 \times 10^{5}$ & $1.4 \times 10^{-4}$ & $1.7 \times 10^{-10}$ \\
$8-3 \mathrm{~S}$ & $7.6 \times 10^{5}$ & $8.4 \times 10^{-5}$ & $1.1 \times 10^{-10}$ \\
\hline
\end{tabular}

Fig. $4 a \& b$ 


\section{a}

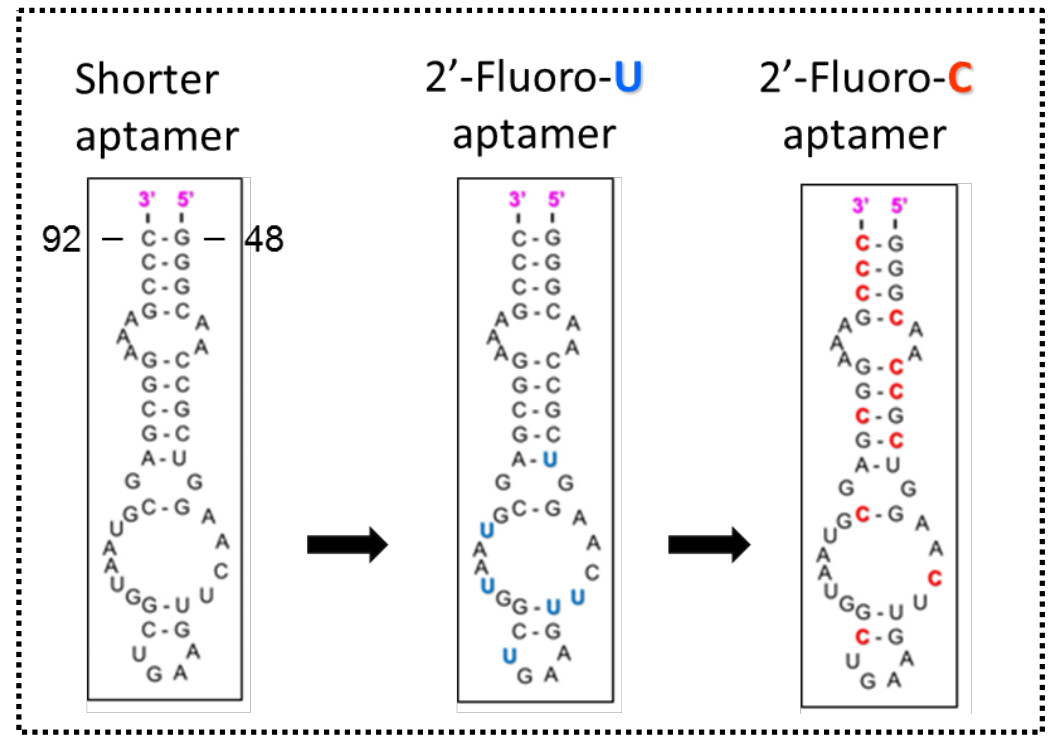

b

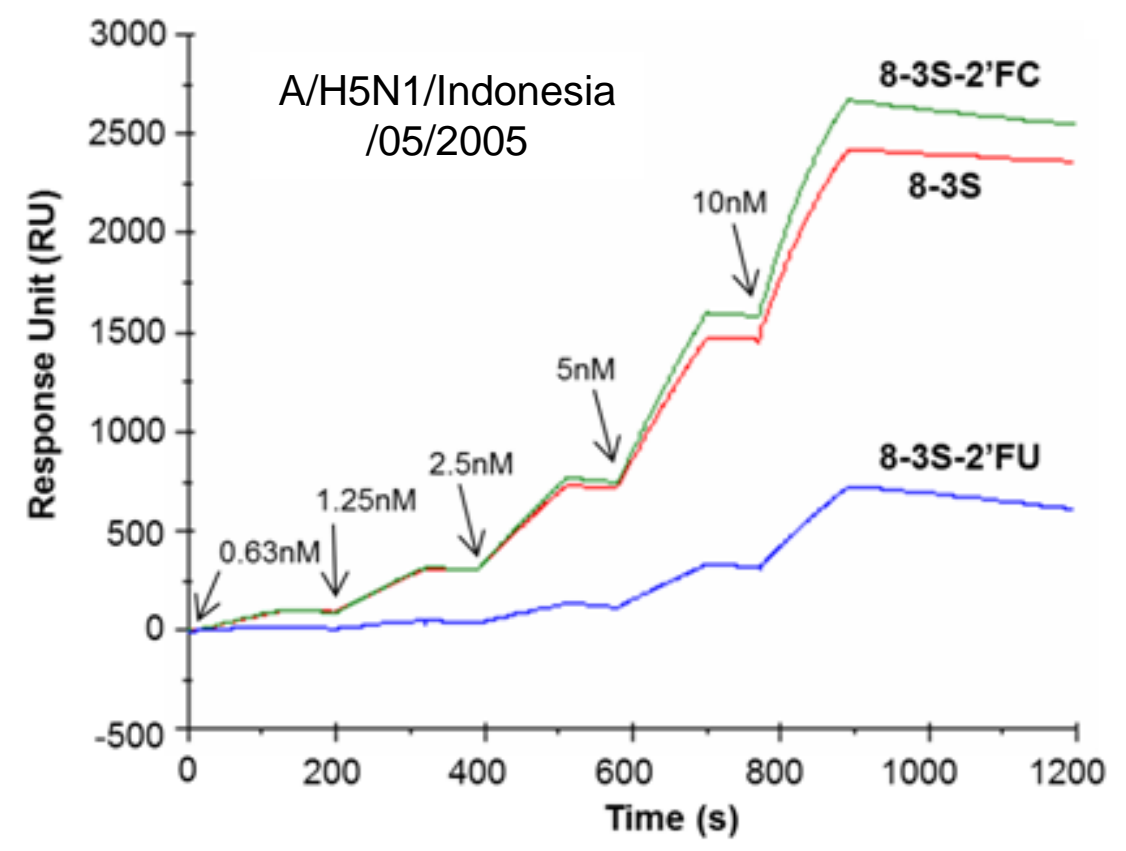

Fig. $5 a \& b$ 
a

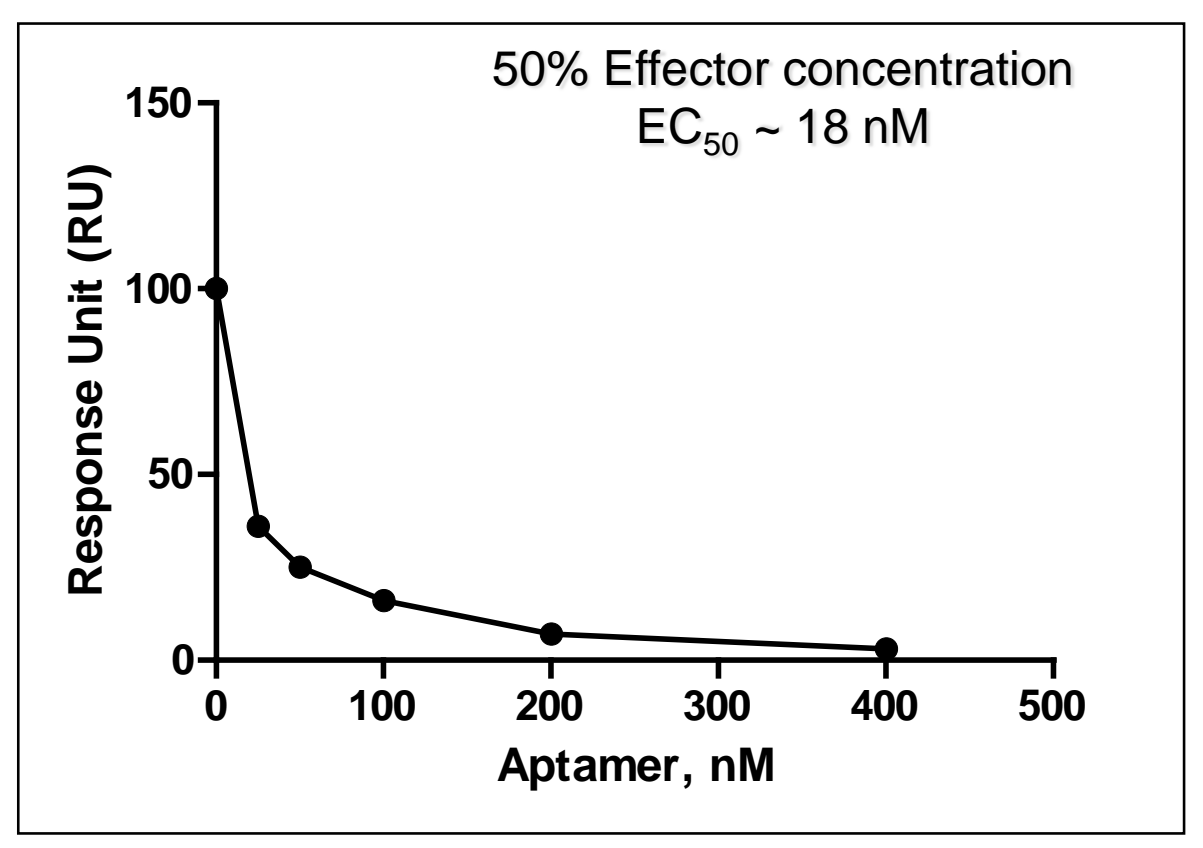

b

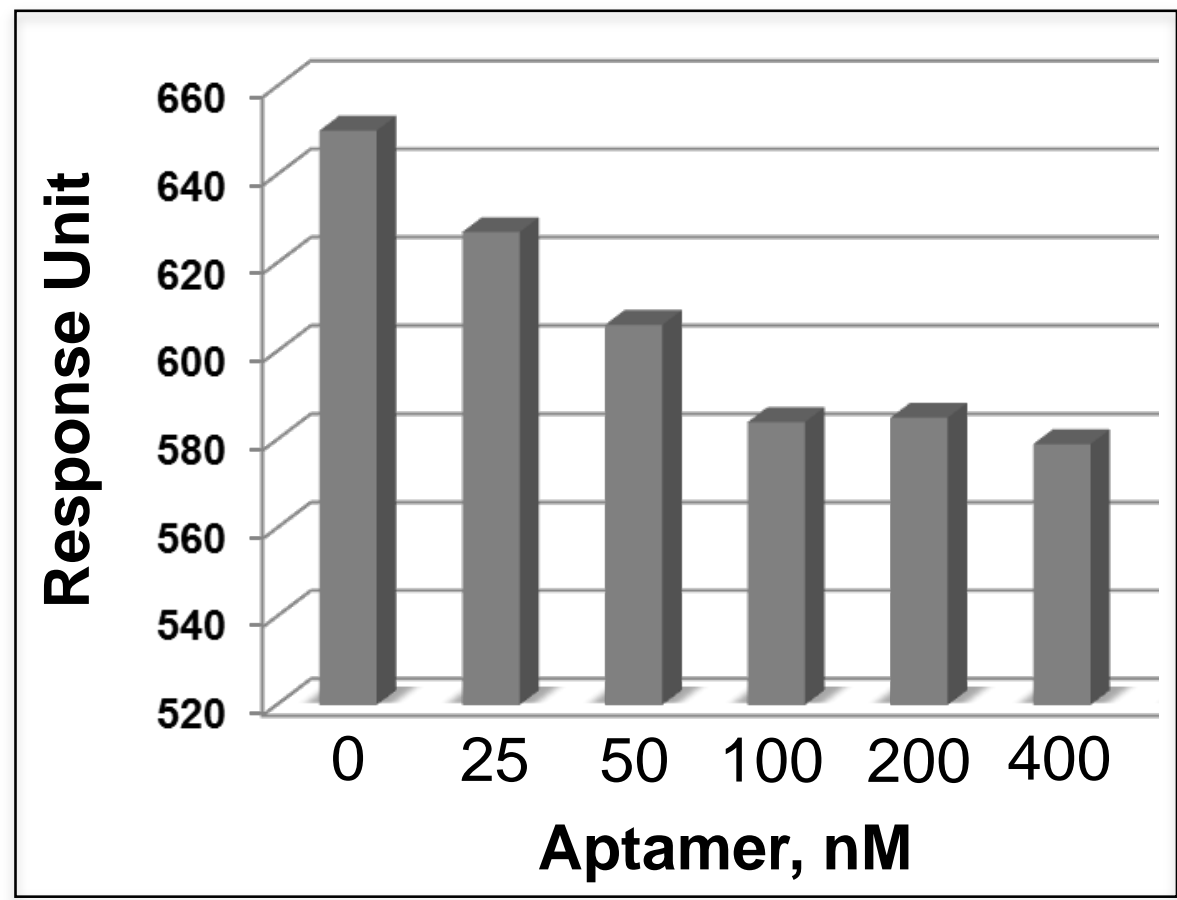

Fig. $6 a \& b$ 


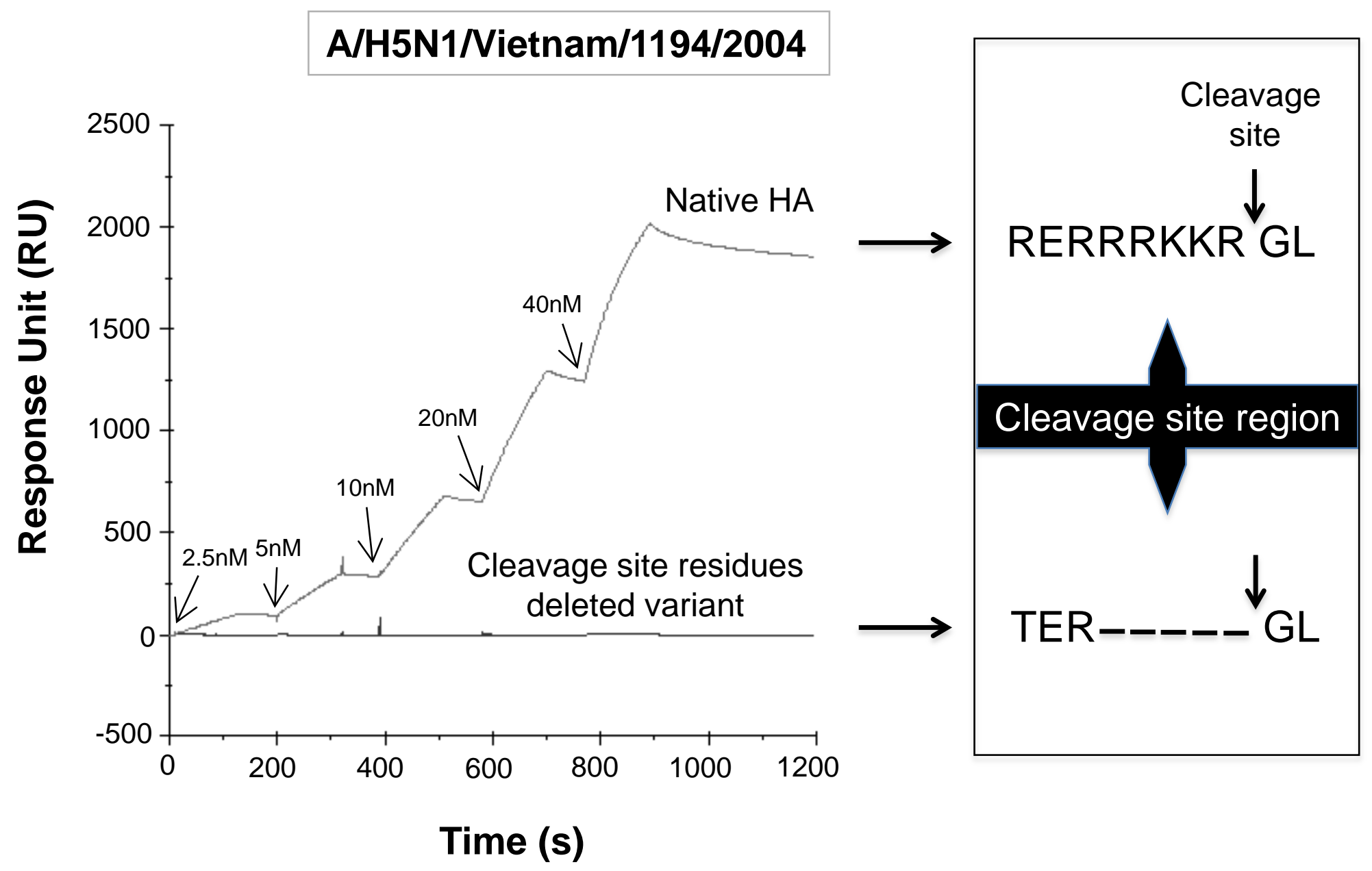

Fig. 7a 


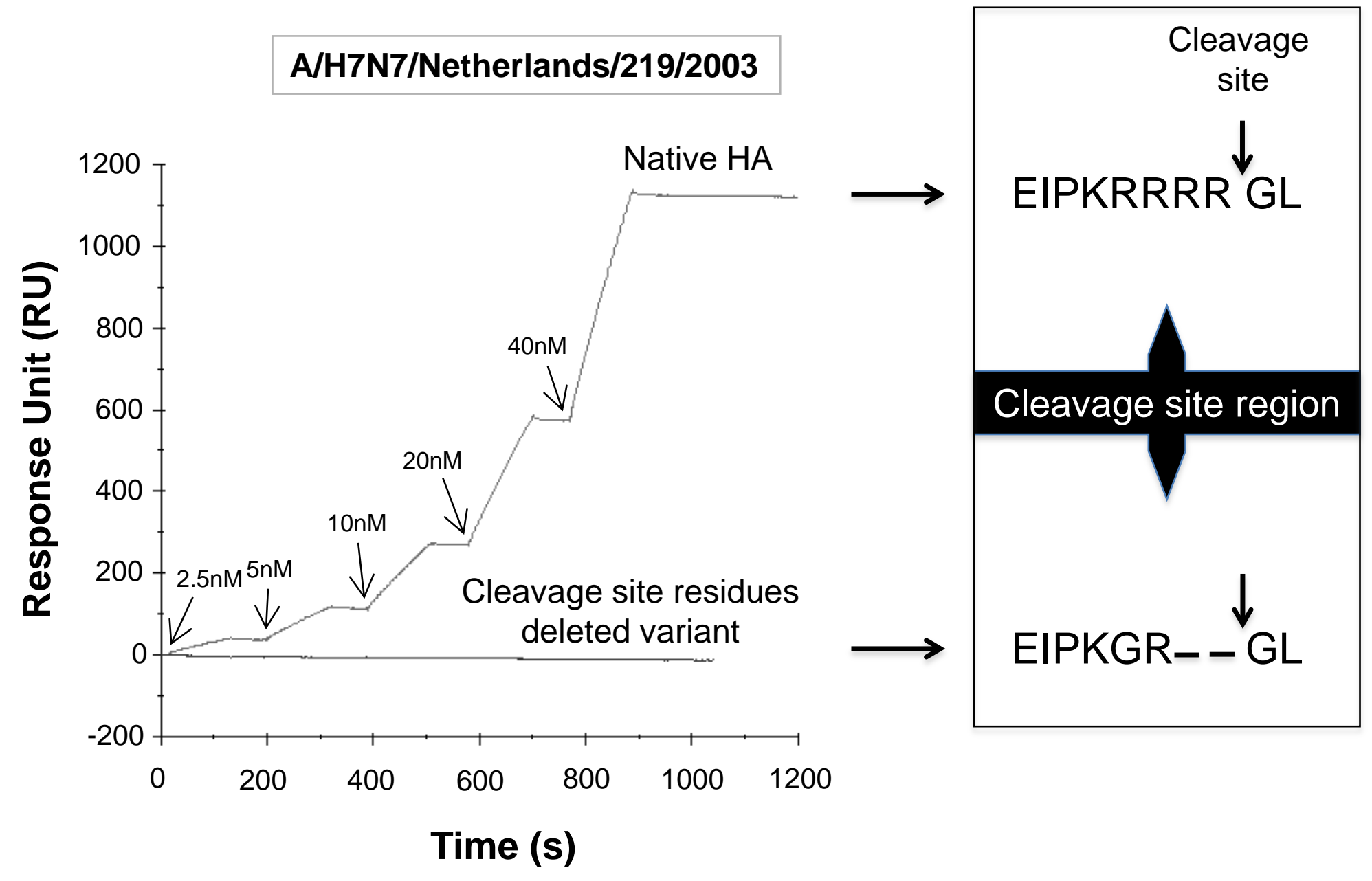

Fig. 7b 
Table 1. Aptamer selection using the HA of the A/H5N1/Vietnam/1194/ 2004 influenza virus

\begin{tabular}{|ccccc|}
\hline $\begin{array}{c}\text { Cycle } \\
\text { no. }\end{array}$ & $\begin{array}{c}\text { RNA:Protein } \\
\text { (Ratio) }\end{array}$ & $\begin{array}{c}\text { Competitor } \\
(\mu \mathrm{M})\end{array}$ & $\begin{array}{c}\text { PCR } \\
\text { Cycles }\end{array}$ & $\begin{array}{c}\text { Filter } \\
\text { Binding (\%) }\end{array}$ \\
1 & $10: 01$ & 10 & 14 & \\
$2^{\star}$ & & 10 & 12 & \\
3 & $4: 01$ & 10 & 12 & \\
$4^{*}$ & & 10 & 18 & \\
5 & $8: 01$ & 10 & 12 & \\
$6^{\star}$ & & 10 & 12 & \\
7 & $4: 01$ & 10 & 10 & \\
$8^{\star}$ & & 10 & 12 & \\
9 & $1: 10$ & 1.6 & 12 & \\
10 & $1: 10$ & 1.6 & 12 & \\
\hline
\end{tabular}

* Xenobind plate selections 


\section{Table 2. Rate constants for the binding of aptamer 8-3 to HAs derived from different sub-types of influenza $A$ virus}

\begin{tabular}{|c|c|c|c|c|c|}
\hline \multirow{10}{*}{$8-3$} & \multirow{8}{*}{ 론 } & & $\begin{array}{l}\text { Association } \\
\text { constant }(k a) \\
\quad(1 / \mathrm{Ms})\end{array}$ & $\begin{array}{l}\text { Dissociation } \\
\text { constant }(\boldsymbol{k d}) \\
\quad(1 / \mathrm{s})\end{array}$ & $\begin{array}{l}\text { Equilibrium Dissociation } \\
\text { constant }\left(K_{D}\right) \\
\text { (M) }\end{array}$ \\
\hline & & \multirow{2}{*}{$\begin{array}{l}\text { A/H5N1/Vietnam/ } \\
1194 / 2004\end{array}$} & $1.1 \times 10^{6}$ & $1.7 \times 10^{-4}$ & $* 1.6 \times 10^{-10}$ \\
\hline & & & $4.0 \times 10^{5}$ & $3.0 \times 10^{-4}$ & $7.5 \times 10^{-10}$ \\
\hline & & \multirow{2}{*}{$\begin{array}{l}\text { A/H5N1/Indonesia/ } \\
\text { 05/2005 }\end{array}$} & $6.1 \times 10^{5}$ & $5.3 \times 10^{-4}$ & $* 8.7 \times 10^{-10}$ \\
\hline & & & $8.4 \times 10^{5}$ & $1.4 \times 10^{-4}$ & $1.7 \times 10^{-10}$ \\
\hline & & \multirow{2}{*}{$\begin{array}{l}\text { A/H7N7/Netherlands/ } \\
\text { 219/2003 }\end{array}$} & $3.5 \times 10^{6}$ & $6.4 \times 10^{-4}$ & $* 1.8 \times 10^{-10}$ \\
\hline & & & $3.0 \times 10^{5}$ & $1.2 \times 10^{-4}$ & $4.2 \times 10^{-10}$ \\
\hline & & $\begin{array}{l}\text { A/H9N2/Hongkong/ } \\
\text { 1073/99 }\end{array}$ & $1.3 \times 10^{5}$ & $3.3 \times 10^{-2}$ & $2.6 \times 10^{-7}$ \\
\hline & \multirow{2}{*}{ 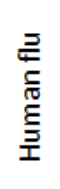 } & $\begin{array}{l}\text { A/H1N1/California/ } \\
\text { 04/2009 }\end{array}$ & $1.4 \times 10^{4}$ & $2.3 \times 10^{-3}$ & $* 1.7 \times 10^{-7}$ \\
\hline & & $\begin{array}{l}\text { A/H3N2/Panama/ } \\
\text { 2007/1999 }\end{array}$ & - & - & * No binding \\
\hline
\end{tabular}

*Deglycosylated HA 
Table 3. Rate constants for the binding of aptamer 8-1 to HAs derived from different sub-types of influenza $A$ virus

\begin{tabular}{|c|c|c|c|c|c|}
\hline \multirow{7}{*}{$8-1$} & \multirow{5}{*}{ 产 } & & $\begin{array}{c}\text { Association } \\
\text { constant (ka) } \\
\text { (1/Ms) }\end{array}$ & $\begin{array}{c}\text { Dissociation } \\
\text { constant }(\boldsymbol{k} d) \\
(1 / \mathrm{s})\end{array}$ & $\begin{array}{l}\text { Equilibrium Dissociation } \\
\text { constant }\left(K_{D}\right) \\
\text { (M) }\end{array}$ \\
\hline & & $\begin{array}{l}\text { A/H5N1/Vietnam/ } \\
\text { 1194/2004 }\end{array}$ & $1.4 \times 10^{4}$ & $3.5 \times 10^{-2}$ & $2.6 \times 10^{-6}$ \\
\hline & & $\begin{array}{l}\text { A/H5N1/Indonesia/ } \\
05 / 2005\end{array}$ & $8.9 \times 10^{4}$ & $2.2 \times 10^{-3}$ & $2.3 \times 10^{-8}$ \\
\hline & & $\begin{array}{l}\text { A/H7N7/Netherlands/ } \\
219 / 2003\end{array}$ & $3.7 \times 10^{4}$ & $2.6 \times 10^{-4}$ & $7.0 \times 10^{-9}$ \\
\hline & & $\begin{array}{l}\text { A/H9N2/Hongkong/ } \\
\text { 1073/99 }\end{array}$ & - & - & No binding \\
\hline & \multirow{2}{*}{ 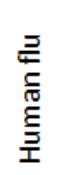 } & $\begin{array}{l}\text { A/H1N1/California/ } \\
\text { 04/2009 }\end{array}$ & - & - & No binding \\
\hline & & $\begin{array}{l}\text { A/H3N2/ Panama/ } \\
\text { 2007/1999 }\end{array}$ & - & - & No binding \\
\hline
\end{tabular}


Table 4. Rate constants for the binding of aptamer 8-10 to HAs derived from different sub-types of influenza $A$ virus

\begin{tabular}{|c|c|c|c|c|c|}
\hline \multirow{7}{*}{$8-10$} & \multirow{5}{*}{$\frac{2}{\frac{2}{4}}$} & & $\begin{array}{l}\text { Association } \\
\text { constant }(k a) \\
\quad(1 / \mathrm{Ms})\end{array}$ & $\begin{array}{c}\text { Dissociation } \\
\text { constant }(\boldsymbol{k} \boldsymbol{d}) \\
\quad(1 / \mathrm{s})\end{array}$ & $\begin{array}{l}\text { Equilibrium Dissociation } \\
\text { constant }\left(K_{D}\right) \\
(\mathrm{M})\end{array}$ \\
\hline & & $\begin{array}{l}\text { A/H5N1/Vietnam/ } \\
\text { 1194/2004 }\end{array}$ & $1.6 \times 10^{4}$ & $1.5 \times 10^{-2}$ & $9.3 \times 10^{-8}$ \\
\hline & & $\begin{array}{l}\text { A/H5N1/Indonesia/ } \\
05 / 2005\end{array}$ & $3.3 \times 10^{4}$ & $1.1 \times 10^{-2}$ & $3.2 \times 10^{-7}$ \\
\hline & & $\begin{array}{l}\text { A/H7N7/Netherlands/ } \\
219 / 2003\end{array}$ & $8.9 \times 10^{3}$ & $1.9 \times 10^{-4}$ & $2.1 \times 10^{-8}$ \\
\hline & & $\begin{array}{l}\text { A/H9N2/Hongkong/ } \\
\text { 1073/99 }\end{array}$ & - & - & No binding \\
\hline & \multirow{2}{*}{ 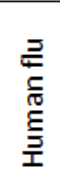 } & $\begin{array}{l}\text { A/H1N1/California/ } \\
04 / 2009\end{array}$ & - & - & No binding \\
\hline & & $\begin{array}{l}\text { A/H3N2/ Panama/ } \\
\text { 2007/1999 }\end{array}$ & - & - & No binding \\
\hline
\end{tabular}




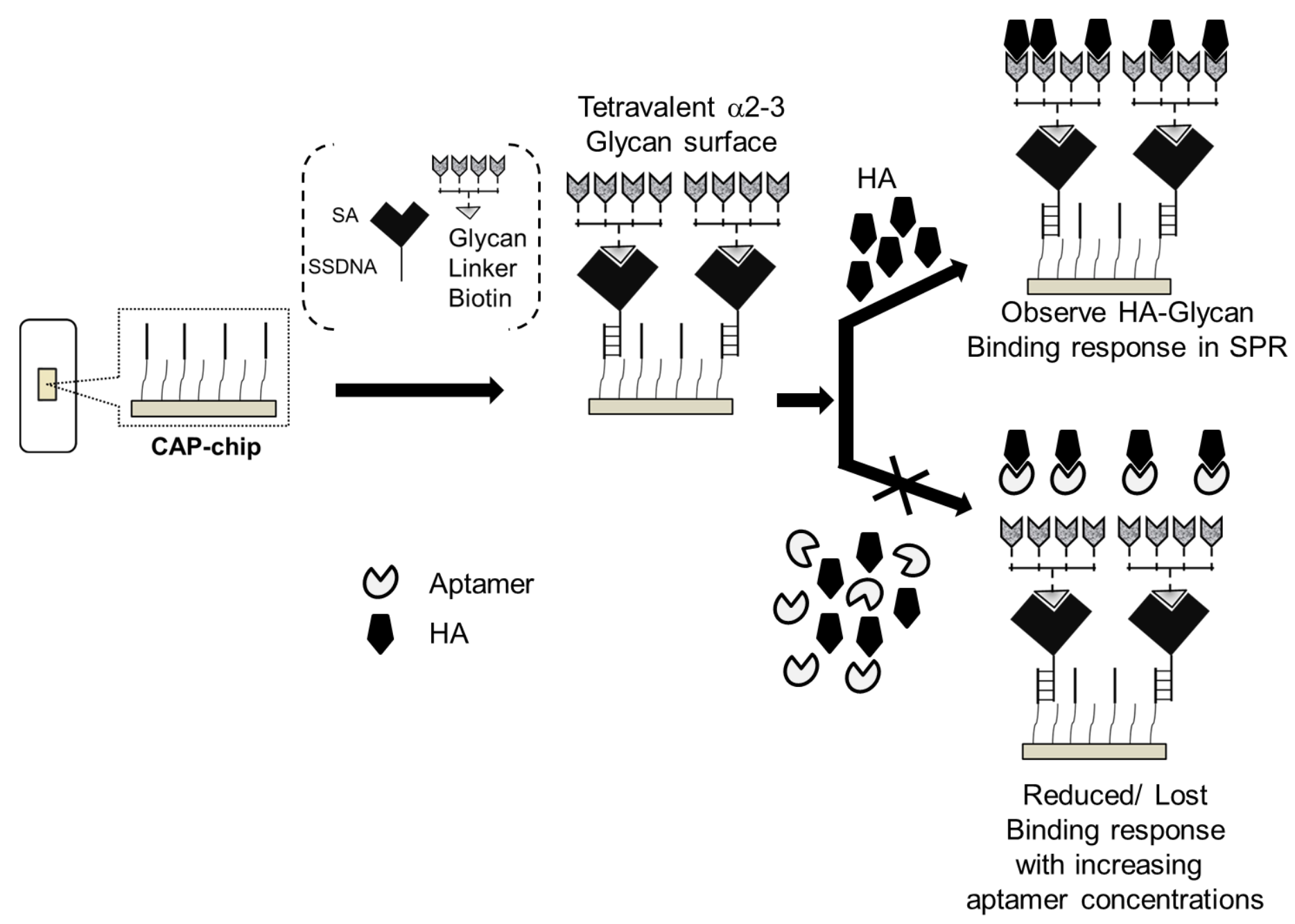

